\title{
Nobel Lecture: The double heterostructure concept and its applications in physics, electronics, and technology*
}

\author{
Zhores I. Alferov \\ A. F. Ioffe Physico-Technical Institute, Russian Academy of Sciences, \\ St. Petersburg 194021, Russian Federation
}

(Published 22 October 2001)

\section{INTRODUCTION}

It is impossible to imagine now modern solid-state physics without semiconductor heterostructures. Semiconductor heterostructures and, particularly, double heterostructures, including quantum wells, wires, and dots, are today the subject of research of two-thirds of the semiconductor physics community.

The ability to control the type of conductivity of a semiconductor material by doping with various impurities and the idea of injecting nonequilibrium charge carriers could be said to be the seeds from which semiconductor electronics developed. Heterostructures developed from these beginnings, making it possible to solve the considerably more general problem of controlling the fundamental parameters inside the semiconductor crystals and devices: band gaps, effective masses of the charge carriers and the mobilities, refractive indices, electron energy spectrum, etc.

Development of the physics and technology of semiconductor heterostructures has resulted in remarkable changes in our everyday life. Heterostructure electronics are widely used in many areas of human civilization. It is hardly possible to imagine our recent life without double heterostructure (DHS) laser-based telecommunication systems, heterostructure-based light-emitting diodes (LED's), heterostructure bipolar transistors, or lownoise high-electron-mobility transistors for highfrequency applications including, for example, satellite television. Double-heterostructure lasers now enter practically every house with $\mathrm{CD}$ players. Heterostructure solar cells have been widely used for space and terrestrial applications.

Our interest in semiconductor heterostructures was not occasional. Systematic studies of semiconductors were started in the early 1930s at the Physico-Technical Institute under the direct leadership of its founder, Abraham Ioffe. V. P. Zhuze and B. V. Kurchatov studied the intrinsic and impurity conductivity of semiconductors in 1932, and the same year Ioffe and Ya. I. Frenkel created a theory of rectification in a metalsemiconductor contact based on the tunneling phenom-

\footnotetext{
*The 2000 Nobel Prize in Physics was shared by Zhores I. Alferov, Jack Kilby, and Herbert Kroemer. This lecture is the text of Professor Alferov's address on the occasion of the award.
}

enon (Frenkel and Ioffe, 1932; Zhuze and Kurchatov, 1932a, 1932b). In 1931 and 1936 Frenkel published his famous articles where he predicted, gave the name, and developed the theory of excitons in semiconductors, and E. F. Gross experimentally discovered excitons in 1951 (Frenkel, 1931, 1936; Gross and Karryev, 1952a, 1952b). The first diffusion theory of $p-n$ heterojunction rectification, which became the base for W. Shockley's $p-n$ junction theory, was published by B. I. Davydov in 1939 (Davydov, 1939). Because of Ioffe's initiative in the late 1940s at the Physico-Technical Institute, research into intermetallic compounds was begun. Theoretical prediction of semiconductor properties in $A^{3} B^{5}$ compounds and their subsequent experimental discovery were done independently by $\mathrm{H}$. Welker and (on the example of InSb) N. A. Gorunova and A. R. Regel at the PhysicoTechnical Institute (Goryunova, 1951; Blum et al., 1952; Welker, 1953). We benefited a lot from the high degree of theoretical, technological, and experimental expertise in this area at the Ioffe Institute at that time.

\section{CLASSICAL HETEROSTRUCTURE}

The idea of using heterojunctions in semiconductor electronics was put forward at the very dawn of the electronic era. In the first patent concerned with $p-n$ junction transistors, Shockley (1951) proposed a wide-gap emitter to obtain unidirectional injection. A. I. Gubanov at our Institute first theoretically analyzed currentvoltage characteristics of isotype and anisotype heterojunctions (Gubanov, 1950, 1951) but the important theoretical considerations at this early stage of heterostructure research were put forward by $\mathrm{H}$. Kroemer, who introduced the concept of quasielectric and quasimagnetic fields in a graded heterojunction and made an assumption that heterojunctions might exhibit extremely high injection efficiencies in comparison to homojunctions (Kroemer, 1957a, 1957b). In the same period there were various suggestions about applying heterostructures in semiconductor solar cells.

The proposal of $p-n$ junction semiconductor lasers (Basov et al., 1961), the experimental observation of effective radiative recombination in GaAs $p$ - $n$ structure with a possible stimulated emission (Nasledov et al., 1962), and the creation of $p-n$ junction lasers and LED's (Hall et al., 1962; Holonyak and Bevacgua, 1962; Nathan et al., 1962) were the seeds from which semiconductor optoelectronics started to grow. However, lasers were 
not efficient because of high optical and electrical losses. The threshold currents were very high, and low temperature was necessary for lasing. The efficiency of LED's was very low, as well, due to high internal losses.

The important step was made immediatly after the creation of $p-n$ junction lasers when the concept of the double heterostructure laser was formulated independently by us and Kroemer (Alferov and Kazarinov, 1963; Kroemer, 1963). In his article Kroemer proposed to use the double heterostructures for carrier confinement in the active region. He proposed that "laser action should be obtainable in many of the indirect gap semiconductors and improved in the direct gap ones, if [it] is possible to supply them with a pair of heterojunction injectors."

In our patent we also outlined the possibility of achieving a high density of injected carriers and inverse population by "double" injection. We especially pointed out that homojunction lasers "do not provide cw at elevated temperatures," and an additional advantage of DH lasers that we considered was the possibility "to enlarge the emitting surface and to use new materials in various regions of the spectrum."

Initially the theoretical progress was much faster than experimental realization. In 1966 (Alferov et al., 1966), we predicted that the density of injected carriers could exceed the carrier density in a wide-gap emitter by several orders of magnitude (the "superjunction" effect). The same year, in a paper submitted to a new Soviet journal, Fizika i Tekhnika Poluprovodnikov (Soviet Physics Semiconductors), I summarized our understanding of the main advantages of the double heterostructure for different devices, especially for lasers and highpower rectifiers:

"The recombination, light-emitting, and population inversion zones coincide and are concentrated in the middle layer. Due to potential barriers at the boundaries of semiconductors having forbidden bands of different width, the through currents of electrons and holes are completely absent, even under strong forward voltages, and there is no recombination in the emitters (in contrast to $p-i-n, p-n-n^{+}, n-p-p^{+}$homostructures, in which the recombination plays the dominant role) ... . Because of a considerable difference between the permittivities, the light is completely concentrated in the middle layer, which acts as a high-grade waveguide, and thus there are no light losses in the passive regions (emitters)" (Alferov, 1966).

Here are the most important peculiarities of semiconductor heterostructures we emphasized at that time: (i) superinjection of carriers, (ii) optical confinement, and (iii) electron confinement.

The realization of the wide-gap window effect was very important for photodetectors, solar cells, and LED applications. It permitted us to broaden considerably and to control precisely the spectral region for solar cells and photodetectors and to improve drastically the efficiency of LED's. The main physical phenomena in
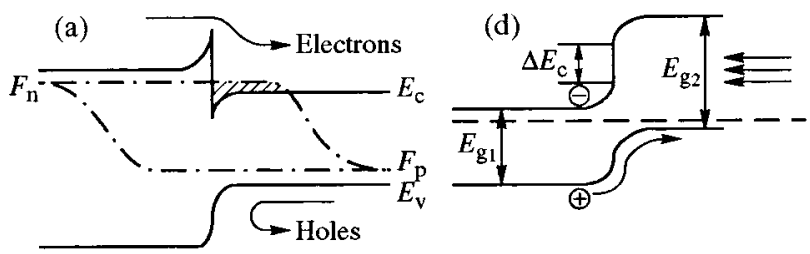

(b)
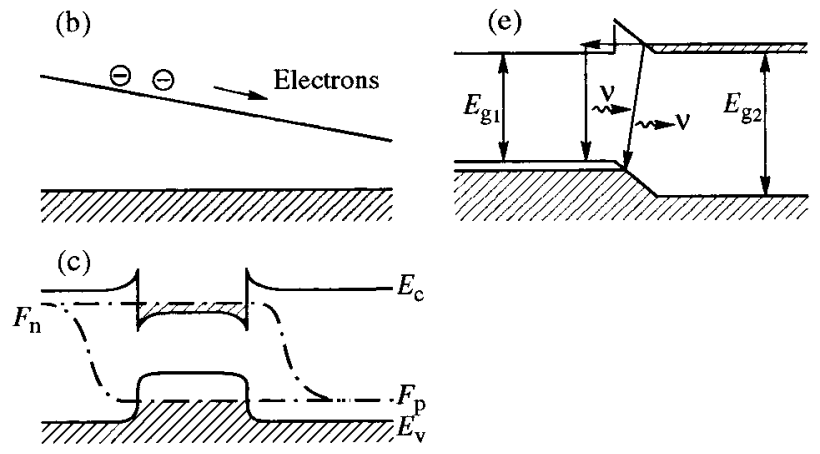

FIG. 1. Main physical phenomena in classical heterostructures: (a) One-side injection and superinjection; (b) diffusion in built-in quasielectric field; (c) electron and optical confinement; (d) wide-gap window effect; (e) diagonal tunneling through a heterostructure interface.

double and single classical heterostructures are shown in Fig. 1. Then it was only necessary to find heterostructures in which these phenomena could be realized.

At that time general skepticism existed with respect to the possibility of creating the "ideal" heterojunction with a defect-free interface and first of all with theoretical injection properties. Even a very pioneering study of the first lattice-matched epitaxially grown single-crystal heterojunctions Ge-GaAs by R. L. Anderson (1960, 1962) did not give any proof of the injection of nonequilibrium carriers in heterostructures. Actual realization of an efficient wide-gap emitter was considered to be next to impossible, and the patent for the doubleheterostructure laser was often referred to as a "paper patent."

Mostly due to this general skepticism there existed only a few groups trying to find the "ideal couple," which was, naturally, a difficult problem. Many conditions of compatibility needed to be met between thermal, electrical, and crystallochemical properties and between the crystal and the band structure of the contacting materials.

A lucky combination of a number of properties, i.e., a small effective mass and wide energy gap, effective radiative recombination, and a sharp optical absorption edge due to the "direct" band structure, a high mobility at the absolute minimum of the conduction band, and its strong reduction of the nearest minimum at the (100) point ensured for GaAs even at that time a place of honor in semiconductor physics and electronics. Since the maximum effect is obtained by using heterojunctions between the semiconductor serving as the active region and a more wideband material, the most promising systems looked at in that time were GaP-GaAs and AlAsGaAs. To be compatible, materials of the "couple" should have, as the first and the most important condi- 
tion, close values of the lattice constants; therefore heterojunctions in the system AlAs-GaAs were preferable. However, prior to starting work on the preparation and study of these heterojunctions one had to overcome a certain psychological barrier. AlAs had been synthesized long ago (Natta and Passerini, 1928; Goldschmidt, 1929), but many properties of this compound remained unstudied, since AlAs was known to be chemically unstable and to decompose in moist air. The possibility of preparing stable and adequate applications of heterojunctions in this system seemed to be not very promising.

Initially, our attempts to create double heterostructures were related to a lattice-mismatched GaAsP system. And we succeeded in fabricating by vapor-phase epitaxy the first DHS lasers in this system. However, due to lattice mismatch, the lasing, like that in homojunction lasers, occurred only at liquid-nitrogen temperatures (Alferov, Garbuzov, et al., 1967). I would like to mention that, curiously, it was the first practical result obtained for a lattice-mismatched, even partially relaxed, system.

Our experience, which we got from studying the GaAsP system, was very important for understanding many specific heterojunction physical properties and the basics of heteroepitaxy. The development of the multichamber vapor-phase epitaxy method for the GaAsP system permitted us to create in 1970 superlattice structures with a $200-\AA$ period and to demonstrate the splitting of the conduction band (Alferov, Zhilyaev, and Shmartsev, 1971).

But from the general point of view at the end of 1966 we came to a conclusion that even a small lattice mismatch in heterostructures $\mathrm{GaP}_{0.15} \mathrm{As}_{0.85}$-GaAs did not permit us to realize potential advantages of the double heterostructure. At that time my co-worker D. N. Tret'yakov told me that some small crystals of $\mathrm{Al}_{x} \mathrm{Ga}_{1-x} \mathrm{As}$ solid solutions of different compositions, which had been prepared two years ago by cooling from a melt, were put in a desk drawer by Dr. A. S. Bortshevsky and nothing happened to them. It immediately became clear that $\mathrm{Al}_{x} \mathrm{Ga}_{1-x}$ As solid solutions turned out to be chemically stable and suitable for the preparation of durable heterostructures and devices. Studies of phase diagrams and the growth kinetics in this system and development of the liquid-phase epitaxy method, especially for heterostructure growth, soon resulted in fabrication of the first lattice-matched AlGaAs heterostructures. When we published the first paper on this subject, we felt lucky to be the first to find a unique, practically ideal lattice-matched system for GaAs, but as frequently happened, simultaneously and independently the same results were achieved by H. Rupprecht and J. Woodall at the T. Watson IBM Research Center (Alferov, Andreev, et al., 1967; Rupprecht et al., 1967).

From then on, progress in the semiconductor heterostructure area was very rapid. First of all, we experimentally proved the unique injection properties of the widegap emitters and superinjection effect (Alferov, Andreev, et al., 1968a) and the stimulated emission in AlGaAs double heterostructures (Alferov, Andreev, et al., 1968b), established the band diagram of the

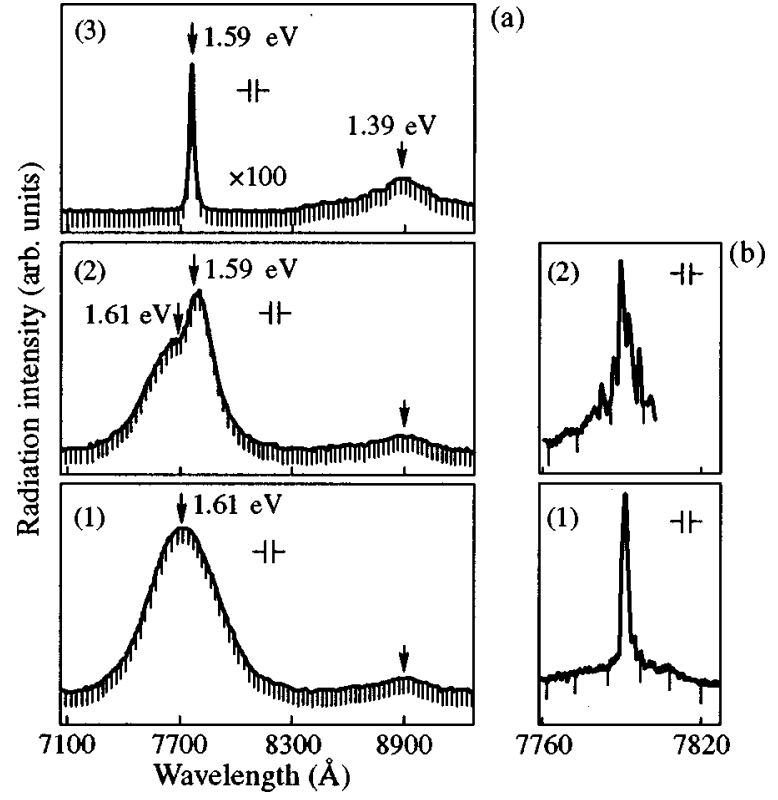

FIG. 2. Emission spectrum of the first low-threshold $\mathrm{Al}_{x} \mathrm{Ga}_{1-x}$ double heterostructure $1 J_{\text {th }}=4300 \mathrm{~A} / \mathrm{cm}^{2}$. The current rises (a) from (1) $0.7 \mathrm{~A}$ to (2) $8.3 \mathrm{~A}$ and then to (3) $13.6 \mathrm{~A}$; $s=2.2$ $\times 10^{-3} \mathrm{~cm}^{2}$.

$\mathrm{Al}_{x} \mathrm{Ga}_{1-x} \mathrm{As}-\mathrm{GaAs}_{x}$ heterojunction, and carefully studied luminescence properties, diffusion of carriers in a graded heterostructure, and very interesting peculiarities of the current flow through the heterojunction. The current flow is similar, for instance, to diagonal tunneling-recombination transitions directly between holes of the narrow-band and electrons of the wide-band heterojunction components (Alferov, Andreev, Korol'kov, Portnoi, and Tret'yakov, 1969; Alferov, Andreev, Korol'kov, Portnoi, and Yakovenko, 1969a; Alferov, Garbuzov, et al., 1969; Alferov, 1970).

At the same time, we created some important devices that realized the main advantages of the heterostructure concepts:

-DHS lasers with low threshold at room temperature. (Fig. 2) (Alferov, Andreev, Portnoy, and Trukan, 1969)

- Highly effective LED's using semiconductor heterostructures and double heterostructures (Alferov, Andreev, Korol'kov, Portnoi, and Yakovenko, 1969b)

-Heterostructure solar cells (Alferov, Andreev, Kagan, et al., 1970)

- Heterostructure bipolar transistor (Alferov, Ahmedov, et al., 1973)

-Heterostructure $p-n-p-n$ switching devices (Alferov, Andreev, Korol'kov, Nikitin, and Yakovenko, 1970).

One of the first successful applications in industrialscale production in our country was heterostructure solar cells in space research. We transferred our technology to the Quant company and, since 1974, GaAlAs solar cells have been installed on many of our sputniks. Our space station Mir (Fig. 3) used them for 15 years.

Most of these results were achieved afterwards in other laboratories in one to two years and in some cases 


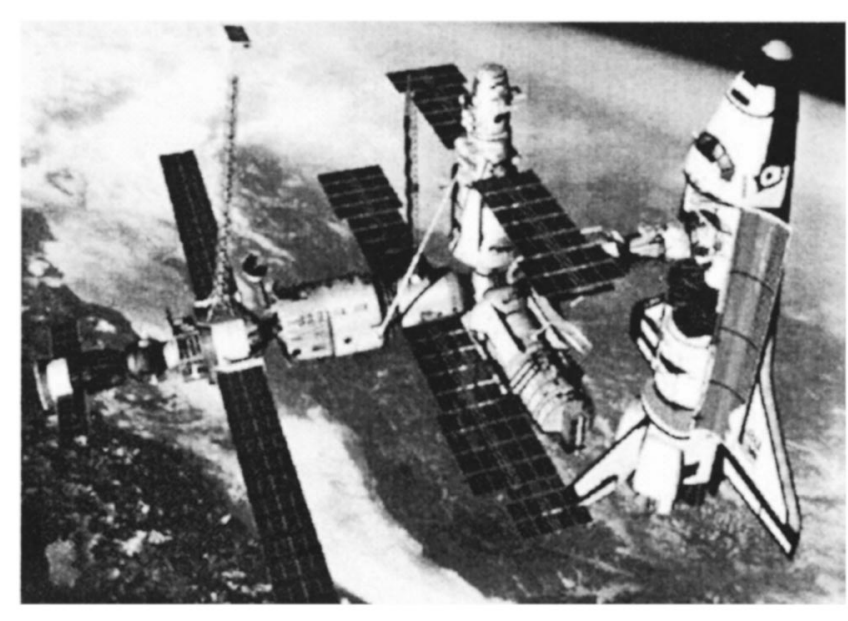

FIG. 3. Space station Mir equipped with heterostructure solar cells.

even later. But in 1970 the international competition became very strong. Later on, one of our main competitors, Izuo Hayashi, who was working together with M. Panish at Bell Telephone Laboratories in Murray Hill, wrote:

"In September 1969 Zhores Alferov of the Ioffe Institute in Leningrad visited our laboratory. We realized he was already getting a $J_{\text {th }}^{(300)}$ of $4.3 \mathrm{kA} / \mathrm{cm}^{2}$ with a DH. We had not realized that the competition was so close and redoubled our efforts... Roomtemperature $\mathrm{cw}$ operation was reported in May 1970 ... " (Hayashi, 1984).

In our paper published in 1970 (Alferov, Andreev, Garbuzov, et al., 1970), cw lasing was realized in stripegeometry lasers formed by photolithography and mounted on copper plates covered by silver (Fig. 4). The lowest $J_{\text {th }}$ density at $300 \mathrm{~K}$ was $940 \mathrm{~A} / \mathrm{cm}^{2}$ for broad-area lasers and $2.7 \mathrm{kA} / \mathrm{cm}^{2}$ for stripe lasers. Independently, cw operation in DHS lasers was reported by Hayashi and Panish (Hayashi et al., 1970; for broad-area lasers with diamond heat sinks) in a paper submitted only one month later than our work. Achievement of continuous waves at room temperature produced an explosion of interest in the physics and technology of semiconductor heterostructures. Whereas in 1969 AlGaAs heterostructures were studied in just a few laboratories, mostly in the USSR and U.S. (A. F. Ioffe Institute, Polyus, and Quant-industrial labs where we transferred our tech-

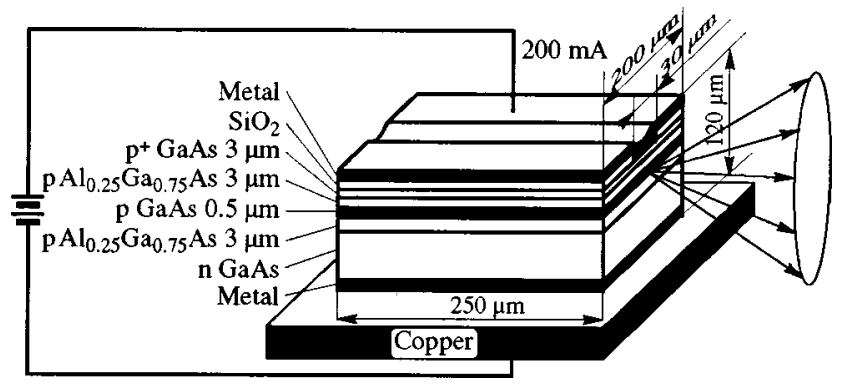

FIG. 4. Schematic view of the structure of the first injection DHS laser operating in the $\mathrm{cw}$ regime at room temperature.

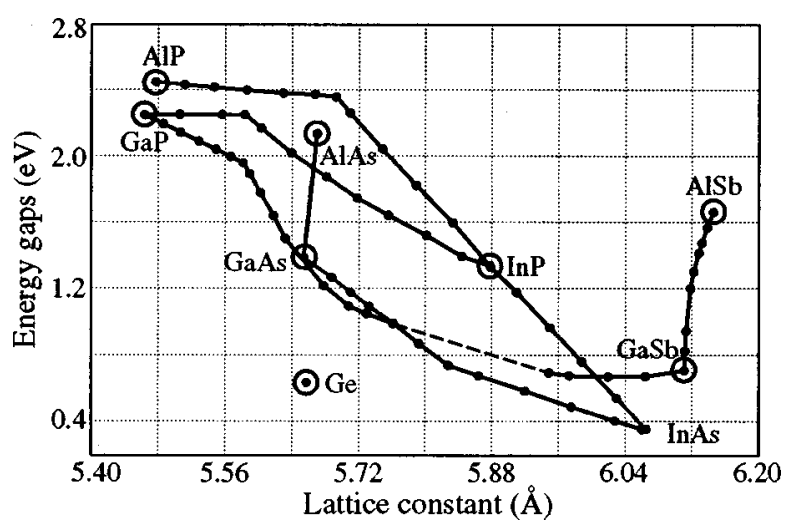

FIG. 5. Energy gaps vs lattice constant for III-V semiconductors. Lattice-matched heterojunctions: Ge-GaAs-1959. From Anderson, 1960, 1962. AlGaAs-1967. From Alferov et al., 1967; Rupprecht et al., 1967. Quaternary heterostructure (InGaAsP and AlGaAsSb): Proposal-1970. From Alferov, Andreev, Konnikov, et al., 1971; First experiment-1972. From Antipas et al., 1973.

nology for applications in the USSR; Bell Telephone, the D. Sarnoff RCA Research Center, and T. J. Watson IBM Research Center in the U.S.), by the beginning of 1971 many universities and industrial labs in the U.S., the USSR, the United Kingdom, Japan, and even Brazil and Poland had begun investigations of III-V heterostructures and heterostructure devices.

At this early stage in the development of heterostructure physics and technology it became clear that we needed to look for new lattice-matched heterostructures in order to cover a broad area of the energy spectrum. The first important step was taken in our laboratory in 1970: in our paper (Alferov, Andreev, Konnikov, et al., 1971) we reported that various lattice-matched heterojunctions based on quaternary III-V solid solutions were possible, which permitted independent variation between lattice constant and band gap. Later on G. Antipas and co-workers came to the same conclusions (Antipas et al., 1973). As a practical example utilizing this idea we considered different InGaAsP compositions, and soon this material was recognized as being among the most important ones, for many different practical applications, including photocathodes (James et al., 1973) and especially lasers in the infrared region for fiber-optic communications (Bogatov et al., 1974) and the visible (Alferov, Arsent'ev, et al., 1975a, 1975b; Hitchins et al., 1975).

The early 1970s "world map" of ideal lattice-matched heterostructures is shown in Fig. 5. Only a decade later this "world map" was drastically changed (Fig. 6). Nowadays, it is necessary to add III nitrides.

The main ideas of a semiconductor distributedfeedback laser were formulated by us in our 1971 patent (Alferov, Andreev, Kazarinov, et al., 1971). The same year H. Kogelnilk and C. V. Shank considered the possibility of replacing the Fabry-Perot or similar types of resonator in dye lasers with volume periodic inhomogeneities (Kogelnik and Shank, 1971). It is necessary to note that their approach is not applicable to semiconductor lasers, and all laboratories that carried out re- 


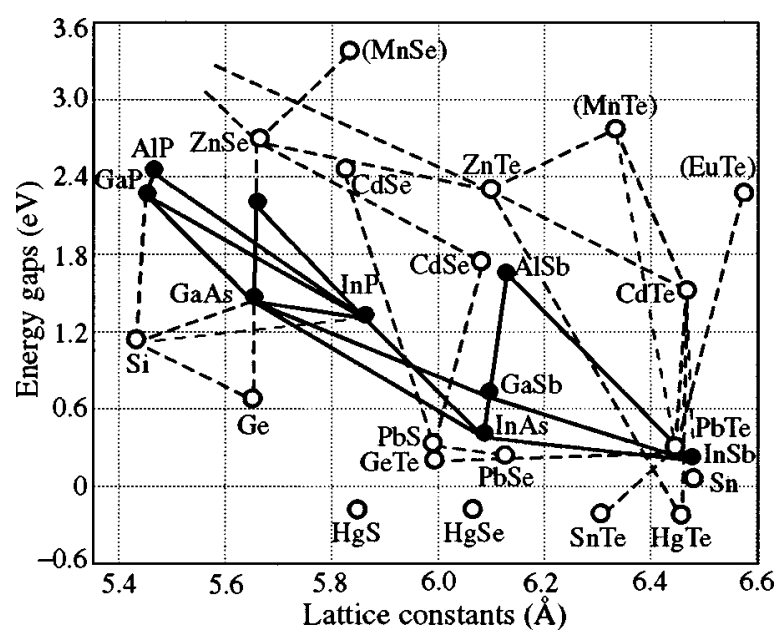

FIG. 6. Energy gaps vs lattice constants for semiconductors of IV elements, III-V and II(IV)-VI compounds, and magnetic materials in parentheses. Lines connecting the semiconductors, solid for the III-V's and dashed for the others, indicate quantum heterostructures that have been investigated.

search in distributed-feedback and distributed-Braggreflector semiconductor lasers used the ideas formulated in Alferov, Andreev, Kazarinov, et al. (1971):

(1) Diffraction grating created not in volume, but on a surface waveguide layer.

(2) Interaction of waveguide modes with a surface diffraction grating, which gives not only distributed feedback but also highly collimated light output.

A detailed theoretical analysis of the semiconductor laser with surface diffraction grating was published in 1972 (Kazarinov and Suris, 1972b). In this paper the authors established the way to obtain single-frequency generation. The first semiconductor lasers using surface diffraction gratings and distributed feedback were realized practically simultaneously at the Physico-Technical Institute (Alferov et al., 1974, 1975), Caltech (Nakamura et al., 1973), and Xerox Laboratory in Palo Alto (Scifres et al., 1974).

In the early 1980s Kroemer and G. Griffiths (1983) published a paper that stimulated strong interest in staggered-lineup heterostructures (type-II heterojunction). Spatial separation of electrons and holes at the interface results in tunability of their optical properties (Alferov, Garbuzov, et al., 1969; Baranov et al., 1986). Staggered band alignment makes it possible to realize optical emission with a photon energy much smaller than the band-gap energy of each of the semiconductors forming a heterojunction. The demonstration of an injection laser based on a type-II GaInAsSb-GaSb heterojunction (Baranov et al., 1986) showed promise for the creation of effective coherent light sources in the infrared optical range. Radiation in such a device is due to the recombination of electrons and holes localized in self-consistent potential wells at different sides of the heterointerface. Thus type-II heterostructures open possibilities both for fundamental physics and for device applications, which cannot be realized with type-I heterostructures in the III-V material systems. However, practical applications of these structures are still hampered by a poor understanding of their fundamental properties and scarcity of actual systems, which have been studied experimentally up to now.

To summarize this brief review of classical heterostructure development, we can classify the most important as follows:

\section{CLASSICAL HETEROSTRUCTURES}

\section{Fundamental physical phenomena (Fig. 1)}

- One-side injection

- Superinjection

- Diffusion in built-in quasielectric fields

- Electron confinement

- Optical confinement

- Wide-gap window effect

- Diagonal tunneling through heterostructure interface

\section{Important applications in electronics}

- Semiconductor lasers-Low threshold and continuous waves at room temperature, distributed-feedback and distributed-Bragg-reflector lasers, vertical surface emitting lasers, IR type-II heterostructure lasers

- High-efficiently LED's

- Solar cells and photodetectors, based on wide-gap window effect

- Semiconductor integrated optics, based on semiconductor distributed-feedback and distributed-Braggreflector lasers

- Bipolar wide-gap transistors

- Transistors, thyristors, and dynistors with photonic signal transmission

- High-power diodes and thyristors

- Infrared to visible converters

- Efficient cold cathodes

\section{Important technological peculiarities}

- Lattice-matched structures are necessary in principle

- Multicomponent solid solutions are used for lattice matching

- Epitaxial growth technology is needed in principle

Concluding this concise summary of the early development of bulk heterostructures, one may say that the invention of an "ideal" heterojunction and the introduction of the heterostructure concept into semiconductor physics and technology have led to the discovery of new physical effects, pivotal improvement in the characteristics of practically all known semiconductor devices, and the invention of new ones.

\section{HETEROSTRUCTURE QUANTUM WELLS AND SUPERLATTICES}

Owing to electron confinement, the doubleheterostructure laser became an important precursor of the quantum well structure: when a middle layer had a thickness of some hundred angstroms, the electron lev- 
els would split due to the quantum size effect. The development of heterostructure growth techniques made it possibile to fabricate high-quality-double heterostructures with ultrathin layers. Two main methods of growth with very precise control of thickness, planarity, compositions, etc. were developed in the 1970s. A modern molecular-beam epitaxy method became practically important for III-V heterostructure technology due first of all to the pioneering work of A. Cho (1971a, 1971b). Metallo-organic chemical vapor deposition originated from the early work of H. Manasevit (1968) and found broad application in III-V heterostructure research after R. Dupuis and P. Dapkus (1977) reported the roomtemperature injection of AlGaAs DH lasers which had been grown by the metal-organic chemical-vapor deposition method.

Clear manifestation of the quantum size effect in optical spectra of GaAs-AlGaAs semiconductor heterostructures with ultrathin GaAs layers (quantum wells) was demonstrated by Raymond Dingle et al. (1974). The authors observed a characteristic steplike behavior in absorption spectra and systematic shifts of the characteristic energies with a quantum well width decrease.

Studies of superlattices were launched by the work of L. Esaki and R. Tsu (1970), who considered the electron transport in a superlattice, i.e., at an additional periodic potential created by doping or changing the composition of semiconductor materials with the period bigger than, but comparable to, the lattice constant of a crystal. In this "man-made crystal," as Esaki called it, a parabolic band would break into minibands separated by small forbidden gaps and having Brillouin zones determined by this period. Similar ideas were described by L. V. Keldysh (1962) when considering the periodic potential produced on a semiconductor surface by an intense ultrasonic wave. At the Physico-Technical Institute, R. Kazarinov and R. Suris theoretically considered the current flow in superlattice structures in the early 1970s (Kazarinov and Suris, 1971, 1972a, 1973). It was shown that the current between wells determined by tunneling through the potential barriers separated the wells, and the authors predicted very important phenomena: tunneling under the electric field when the ground state of a well coincided with the excited state of the next well, and stimulated emission resulting from photon-assisted tunneling between the ground state of one well and the excited state of a neighboring well, which is lower in energy due to an applied electric field. At that time Esaki and Tsu independently considered resonant tunneling in superlattice structures (Tsu and Esaki, 1973).

The pioneering experimental studies of the superlattice structures were carried out by Esaki and Tsu: the superlattices were grown by vapor-phase epitaxy in the system $\mathrm{GaP}_{x} \mathrm{As}_{1-x}$-GaAs. At the same time, in our laboratory we developed the first multichamber apparatus and, as was mentioned before, prepared a superlattice structure $\mathrm{GaP}_{0.3} \mathrm{Al}_{0.7}$-GaAs with the thickness of each layer $100 \AA$ and a total of 200 layers (Alferov, Zhilyaev, and Shmartsev, 1971). Observed peculiarities of the current-voltage characteristics, their temperature de- pendence, and photoconductivity were explained by the splitting of the conduction band due to the onedimensional periodic potential of the superlattice. These first superlattices were also the first strained-layer superlattices. E. Blakeslee and J. Matthews, who were working with Esaki and Tsu at IBM, succeeded in the mid1970s in growing strained-layer superlattices with a very low concentration of defects. But many years later, after G. Osbourn's (1982) theoretical study at Sandia Lab and the first successful preparation of a high-quality strained-layer superlattice GaAs- $\mathrm{In}_{0.2} \mathrm{Ga}_{0.8} \mathrm{As}$ by M. Ludowise at Varian, N. Holonyak at the University of Illinois achieved on those structures a cw roomtemperature laser action (Ludowise et al., 1983). It became clear that in a strained-layer superlattice the lattice strain became an additional degree of freedom, and by varying the layer thicknesses and compositions one could vary continuously and independently of one another the forbidden gap, lattice constant, of the overall superlattice.

In the early 1970s, Esaki and co-workers moved to molecular-beam epitaxy technology in AlGaAs systems (Chang et al., 1973), and in March 1974 they submitted a paper on resonant tunneling (Chang et al., 1974). It was the first experimental demonstration of quantum well heterostructure physics. They measured the tunneling current and conductance as a function of an applied voltage in GaAs-GaAlAs double barriers and found current maxima associated with resonant tunneling. Later in the same year Esaki and Chang (1974) observed resonant tunneling in a superlattice. The strong interest in resonant tunneling obviously was connected with its potential applications in high-speed electronics. In the late 1980s picosecond operation was achieved in a doubleresonant tunnel diode, and oscillations up to $420 \mathrm{GHz}$ were reported in a GaAs resonant tunnel diode at room temperature.

The restriction of electron motion to two dimensions in field-effect transistors had been recognized long ago (Shriffer, 1957) and that for trapped electrons in inversion layers was first verified in a magnetoconductance experiment by A. B. Fowler et al. (1966). Spectral effects due to spatial quantization were observed in thin bismuth films in 1968 by V. N. Lutskii and L. A. Kulik (Lutskii, 1970).

The pioneering work of Dingle et al. (1978) on modulation-doped superlattices demonstrated a mobility enhancement with respect to the bulk crystal and stimulated research on the application of high-mobility two-dimensional electron gas for microwave amplification. In France and Japan practically simultaneously new types of transistors based on a single $n$ AlGaAs- $n \mathrm{GaAs}$ modulation-doped heterostructure were created that were labeled TEGFET's (twodimensional electron-gas field-effect transistors) in France (Delagebeaudeuf et al., 1980) and HEMT's (high-electron-mobility transistors) in Japan (Mimura et al., 1980).

The first quantum well laser operation was demonstrated by J. P. van der Ziel et al. (1975), but the lasing 
parameters were much worse than for average DHS lasers. In 1978 Dupuis and Dapkus, in collaboration with Holonyak, first reported on a quantum well laser with parameters comparable to those of conventional DHS lasers (Dupuis et al., 1978). The name "quantum well" was used in that paper. The real advantages of quantum well lasers were demonstrated much later by W. T. Tsang at Bell Telephone Laboratories. Thanks to many improvements in molecular-beam epitaxy growth technology and the introduction of an optimized structure (GRIN SCH), he found threshold currents as low as $160 \mathrm{~A} / \mathrm{cm}^{2}$ (Tsang, 1982).

We started to develop molecular-beam epitaxy and metal-organic chemical vapor deposition methods for growing III-V heterostructures only in the late 1970s. First of all, we stimulated the design and construction of the first Soviet molecular-beam epitaxy machine in our electronic industry. In a few years three generations of these machines were developed, and the last, which had the name "Cna," was good enough for our goals. (It was named for the nice river not very far from Ryazan, the city where NITI - the industrial laboratory of the Electronic Industry - was located; NITI carried out development of the molecular-beam epitaxy machine.) In parallel, later on, we started to develop a molecular-beam epitaxy system with NTO AN-the scientific instruments company of the Academy of Sciences in Leningrad. In the mid-1980s we got a few systems of this version. Both types of molecular-beam epitaxy systems are still working at the Ioffe Institute and other laboratories.

We developed the metal-organic chemical vapor deposition systems in our Institute and later, in the 1980s, a Swedish company, Epiquip, specially designed with our participation two systems for our Institute, which are still used in our research.

The strong interest in the experimental study of lowdimensional structures and the lack of equipment for molecular beam epitaxy and metal-organic chemicalvapor deposition growth technology stimulated our research on the development of liquid-phase epitaxy suitable for quantum well heterostructures.

However, until the late 1970s it seemed impossible to grow III-V heterostructures with an active-region thickness of less than $500 \AA$ by liquid-phase epitaxy because of the existence near the heterojunction of extended interface regions with varying chemical compositions.

The situation was changed due to the work of Holonyak et al. (Rezek et al., 1977) for superlatticelike InGaAsP structures, using a rotating boat system. In our laboratory we developed a new liquid-phase epitaxy method with the usual translational motion in a standard horizontal system for InGaAsP heterostructures (Alferov et al., 1985) and a low-temperature liquid-phase epitaxy method for AlGaAs heterostructures (Alferov et al., 1986a). These methods permitted us to prepare practically any kind of excellent-quality quantum well heterostructures with an active-region thickness of up to $20 \AA$ and with the size of the interface regions comparable to one lattice constant. Of great practical impor- (a)

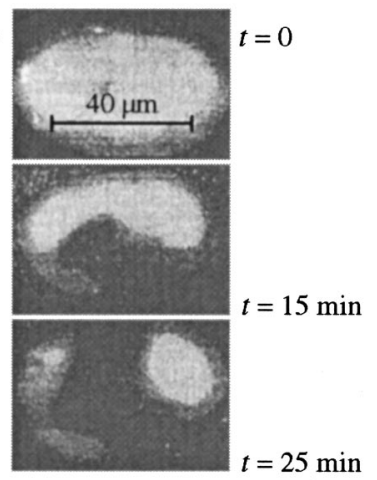

(b)

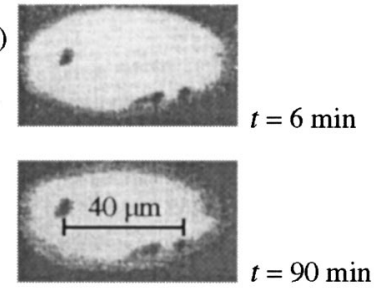

FIG. 7. Time evolution of a double heterostructure active region under high-level photoexcitation: (a) AlGaAs/GaAs, (b) InGaAsP/GaAs. Diameter of $\mathrm{Kr}^{+}$-laser excitation beam -40 $\mu \mathrm{m}$. Excitation level (a) $10^{4} \mathrm{~W} / \mathrm{cm}^{2}$, (b) $10^{5} \mathrm{~W} / \mathrm{cm}^{2}$.

tance for InGaAsP laser heterostructures was the creation of a record threshold current density for InGaAsP/ InP $(\lambda=1.3$ and $1.55 \mu \mathrm{m})$ and for InGaAsP/GaAs $(\lambda$ $=0.65-0.9 \mu \mathrm{m})$ single quantum well separate confinement lasers (Alferov et al., 1986b, 1987). For high-power InGaAsP/GaAs $(\lambda=0.8 \mu \mathrm{m})$ lasers a total efficiency of $66 \%$ with $\mathrm{cw}$ power $5 \mathrm{~W}$ for $100 \mu \mathrm{m}$ width, a stripegeometry laser was achieved (Alferov et al., 1988a; Garbuzov et al., 1988). In this laser the effective cooling of a semiconductor power device by recombination radiation was for the first time realized as had been predicted much earlier (Alferov, 1966). Garbuzov et al. (1990) noted an important characteristic of the InGaAsP heterostructure, its unusual resistance to multiplication of dislocations and defects (Fig. 7). It was this research that initiated the broad application of Al-free heterostructures.

A most complicated quantum well laser structure (Fig. 8), which combined a single quantum well with

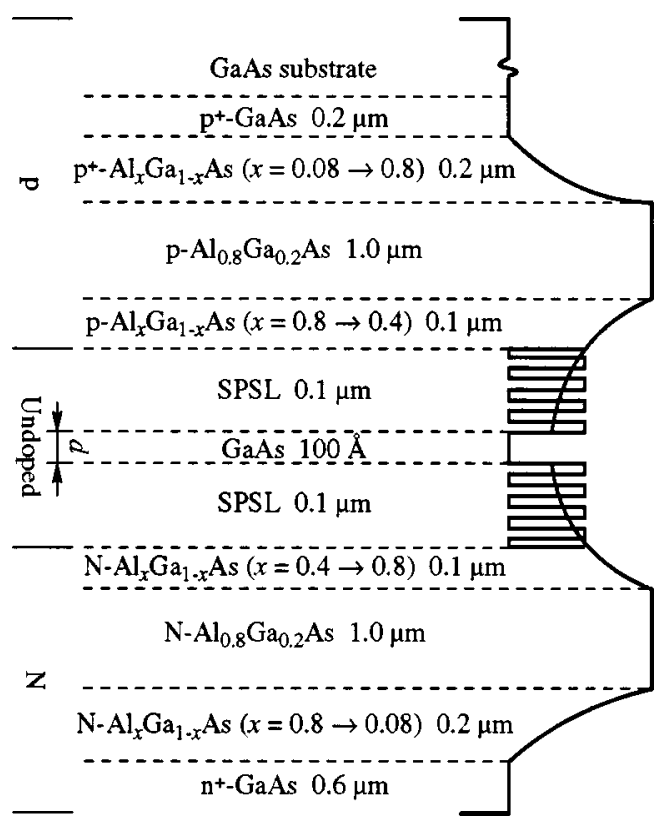

FIG. 8. Quantum well heterostructure laser, using short-period superlattices grown by molecular-beam epitaxy. 


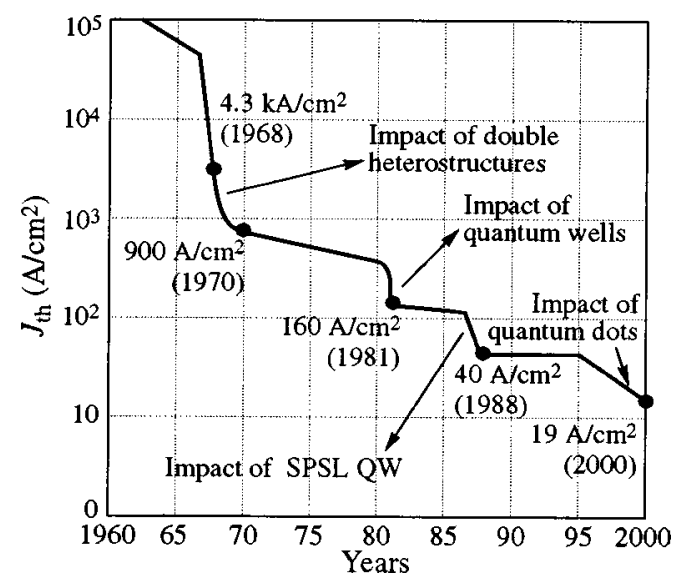

FIG. 9. Evolution of the threshold current of semiconductor lasers.

short-period superlattices, for the creation of GRIN $\mathrm{SCH}$ semiconductor heterostructures (the most favorable for the lowest $J_{\text {th }}$ ) was demonstrated in our laboratory in 1988 (Alferov et al., 1988b). Using short-period superlattices, we achieved not only the desirable profile of a graded waveguide region, thus creating a barrier for dislocation movement to the active layer, but also the possibility of growing different parts of the structure at sufficiently large differences in temperature. In this way, we obtained both an excellent surface morphology and a high internal quantum efficiency on a planar GaAs (100) surface. The lowest $J_{\text {th }}=52 \mathrm{~A} / \mathrm{cm}^{2}$ and, after some small optimization, $40 \mathrm{~A} / \mathrm{cm}^{2}$ was for a long time a world record for semiconductor injection lasers and a good demonstration of the application of quantum wells and superlattices in electronic devices.

The idea of stimulated emission in superlattices which had been suggested by Kazarinov and Suris (1971, 1972a, 1973) was realized nearly a quarter of a century later after a proposal by Federico Capasso (Faist et al., 1994). The proposed structure was strongly improved, and a cascade laser developed by Capasso gave rise to a new generation of unipolar lasers operating in the middle-infrared range.

The history of semiconductor lasers is, from a certain point of view, the history of the evolution of the semiconductor laser current threshold, which is shown in Fig. 9. The most dramatic changes took place just after the introduction of the DHS concept. The impact of shortperiod superlattice quantum wells led to a theoretical limit on this most important parameter. What can happen as a result of application of the new quantum wires and quantum dot structures will be discussed in the next part of our paper.

It may be that the crowning achievement of quantum well studies was the discovery of the quantum Hall effect (Klitzing et al., 1980). This discovery and its comprehensive studies in AlGaAs-GaAs heterostructures, which shortly led to the discovery of the fractional quantum Hall effect (Tsui et al., 1982), had a huge impact on solid-state physics. Observation of the effect, which deals only with fundamental quantities and does not rely on peculiarities of the band structure, carrier mobility, or densities in a semiconductor, has shown that heterostructures can be used to model some very basic physical effects. Recently many studies in this area have concentrated on understanding the condensation of electrons and the search for Wigner crystallization.

To summarize, the development of the field of heterostructure quantum wells and superlattices can be outlined in the same manner as that of classical heterostructure research:

\section{HETEROSTRUCTURE QUANTUM WELLS AND SUPERLATTICES}

\section{Fundamental physical phenomena}

- 2D electron gas

- Steplike density-of-state function

- Quantum Hall effect

- Fractional quantum Hall effect

- Excitons at room temperature

- Resonant tunneling in double-barrier structure and superlattices

- Energy spectrum in superlattices determined by choice of potential and strain

- Stimulated emission at resonant tunneling in superlattices

- Pseudomorphic growth of strained structures

\section{Important consequences for applications}

- Shorter emission wavelength, reduced threshold current, larger differential gain, and reduced temperature dependence of the threshold current for semiconductor lasers

- Infrared quantum cascade laser

- Short-period superlattice quantum well laser

- Optimization of electron and light confinement and waveguiding for semiconductor lasers

- 2D electron-gas transistors (high-electron-mobility transistors)

- Resonant-tunneling diodes

- Precise resistance standards

- SEED's and electro-optical modulators

- Infrared photodetectors based on quantum size level absorption

III. Important technological peculiarities

- Lattice match unnecessary

- Low-growth-rate technology (MBE, MOCVD) needed in principle

- Submonolayer growth techniques used

- Blockading of mismatch dislocations during epitaxial growth

- Sharp increase in the variety of heterostructure components

\section{HETEROSTRUCTURE QUANTUM WIRES AND QUANTUM DOTS}

The principal advantage of using quantum-size heterostructures in lasers is the noticeable increase in the density of states when the dimensionality of the electron gas is reduced (Fig. 10). 

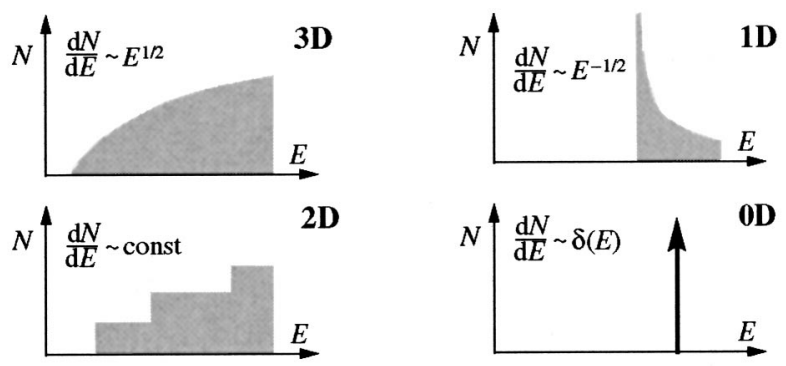

FIG. 10. Density of states for charge carriers in structures with different dimensionalities.

During the 1980s, progress in 2D quantum well heterostructure physics and its applications drew many scientists to the study of systems of far less dimensionality-quantum wires and quantum dots. In contrast to quantum "wells," where carriers are localized in the direction perpendicular to the layers but move freely in the layer plane, in quantum "wires" carriers are localized in two directions and move freely along the wire axis. With confinement in all three directions, quantum "dots"- "artificial atoms" with a totally discrete energy spectrum-are created (Fig. 11).

Experimental work on the fabrication and investigation of quantum wire and dot structures began more than 15 years ago. In 1982, Y. Arakawa and H. Sakaki (1982) theoretically considered some effects in lasers based on heterostructures with size quantization in one, two, and three directions. They wrote: "Most important, the threshold current of such a laser is reported to be far less sensitive than that of [a] conventional laser reflecting the reduced dimensionality of [the] electronic state." The authors performed experimental studies on a quantum well laser placed in high magnetic fields directed perpendicular to the quantum well plane and demonstrated an increase in the characteristic temperature $\left(T_{0}\right)$ describing the exponential growth of the threshold current; the temperature increased in the magnetic field from 144 to $313{ }^{\circ} \mathrm{C}$. They pointed to the possibility of weakening the threshold current dependence on temperature for quantum wire lasers and full temperature stability for quantum dot lasers (Fig. 12). By now there

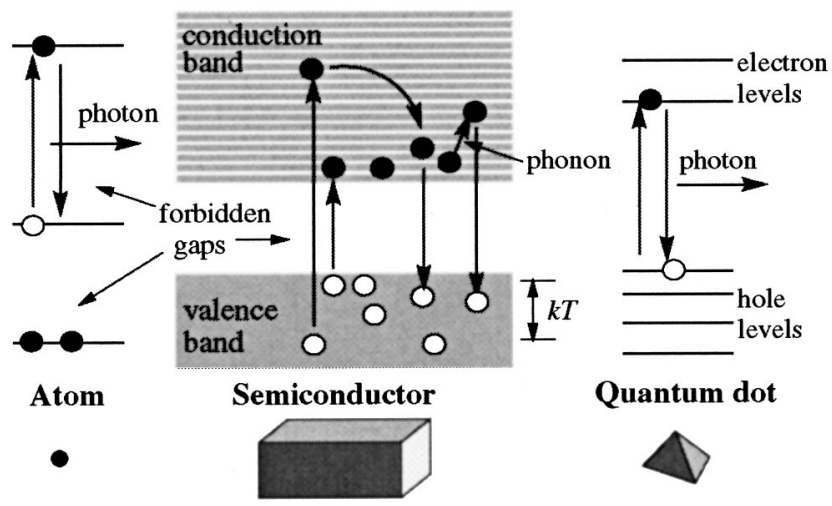

FIG. 11. Schematic representation of energy diagrams for a single atom (left), a bulk crystal (center), and a quantum dot (right).

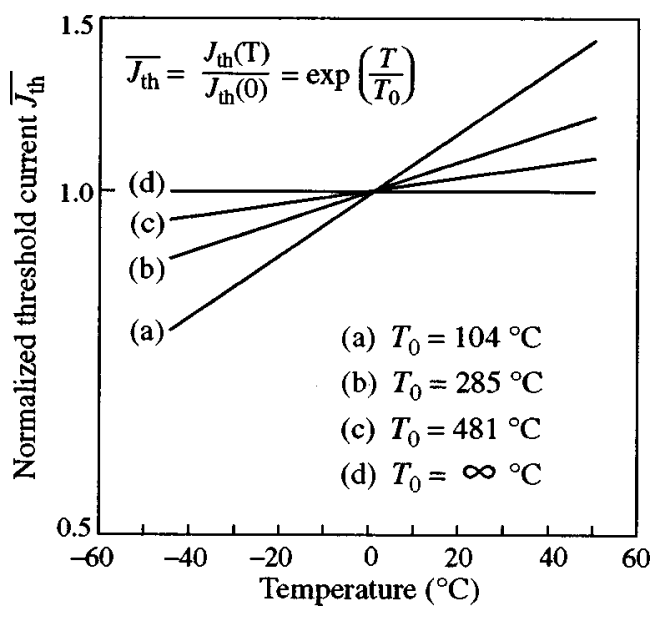

FIG. 12. Normalized temperature dependence of the threshold current for various DHS lasers: (a) bulk; (b) with quantum wells; (c) with quantum wires; (d) with quantum dots.

are many theoretical and experimental papers in this field.

The first semiconductor dots based on II-VI microcrystals in a glass matrix were proposed and demonstrated by A. I. Ekimov and A. A. Onushchenko (1981). However, since the semiconductor quantum dots were introduced in an insulating glass matrix and the quality of the interface between glass and semiconductor dot was not high, both fundamental studies and device applications were limited. Much more exciting possibilities appeared after three-dimensional coherent quantum dots had been fabricated in a semiconductor matrix (Goldstein et al., 1985).

Several methods were proposed for the fabrication of these structures. Indirect methods, such as postgrowth lateral patterning of a 2D quantum well, often suffer from insufficient lateral resolution and interface damage caused by the patterning procedure. A more promising approach is fabrication by direct methods, i.e., growth in $\mathrm{V}$ grooves and on corrugated surfaces, which may result in formation of quantum wires and dots. The groups at the Ioffe Institute and Berlin Technical University-who have carried out this research in close cooperation over the past few years-have contributed significantly to the latter type of fabrication.

These groups came to the conclusion that the most exciting method for forming ordered arrays of quantum wires and dots is use of self-organization phenomena on crystal surfaces. Strain relaxation on step or facet edges may result in the formation of ordered arrays of quantum wires and dots for both lattice-matched and latticemismatched growth. The first very uniform arrays of three-dimensional quantum dots also exhibiting lateral ordering were realized in the system InAs-GaAs by both molecular-beam epitaxy and metal-organic chemicalvapor deposition growth methods (Ledentsov et al., 1995; Alferov, Gordeev, et al., 1996).

Elastic strain relaxation on facet edges and island interaction via the strained substrate are driving forces for the self-organization of ordered arrays of uniform, co- 
(a)

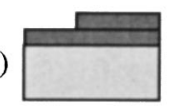

(b)

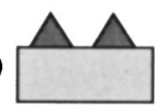

(c)

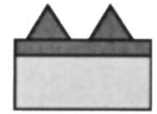

FIG. 13. Growth modes: (a) Frank-van der Merve; (b) Volmer-Weber; (c) Stranski-Krastanow.

herently strained islands on crystal surfaces (Shchukin et al., 1995). In lattice-matched heteroepitaxial systems the growth mode is determined solely by the relation between the energies of two surfaces and the interface energy. If the sum of the surface energy of epitaxial layer $\gamma_{2}$ and the energy of the interface $\gamma_{12}$ is lower than the substrate surface energy, $\gamma_{2}+\gamma_{12}<\gamma_{1}$, i.e., if the material being deposited wets the substrate, then we have Frank-van der Merve growth. Changing the $\gamma_{2}+\gamma_{12}$ value may result in a transition from the Frank-van der Merve mode to a Volmer-Weber one in which 3D islands are formed on a bare substrate.

In a heteroepitaxial system with lattice mismatch between the material being deposited and the substrate, the growth may initially proceed in a layer-by-layer mode. However, a thicker layer has a higher elastic energy, and the elastic energy tends to be reduced via the formation of isolated islands. In these islands the elastic strains relax and, correspondingly, the elastic energy decreases. This results in a Stranski-Krastanow growth mode (Fig. 13). The characteristic size of islands is determined by the minimum in the energy of an array of $3 \mathrm{D}$ coherently strained islands per unit surface area as a function of the island size (Fig. 14) (Shchukin et al., 1995). Interaction between islands via an elastically strained substrate would result in lateral island ordering typical of a square lattice.

Experiments show in most cases a rather narrow size distribution of the islands, and on top of that coherent islands of InAs form under certain conditions a quasiperiodic square lattice (Fig. 15). The shape of quantum dots can be significantly modified during regrowth or postgrowth annealing, or by applying complex growth

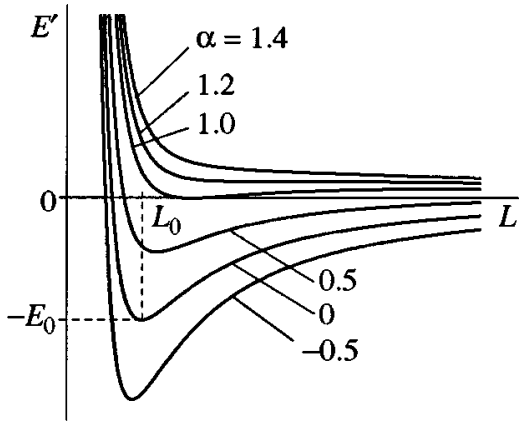

FIG. 14. Energy of a sparse array of 3D coherently strained islands per unit surface area as a function of island size. The parameter $\alpha$ is the ratio between the change in the surface energy upon island formation and the contribution from island edges to the elastic relaxation energy. When $\alpha>1$, the system tends thermodynamically toward island coalescence. When $\alpha$ $<1$, there exists an optimal island size and the system of islands is stable against coalescence.

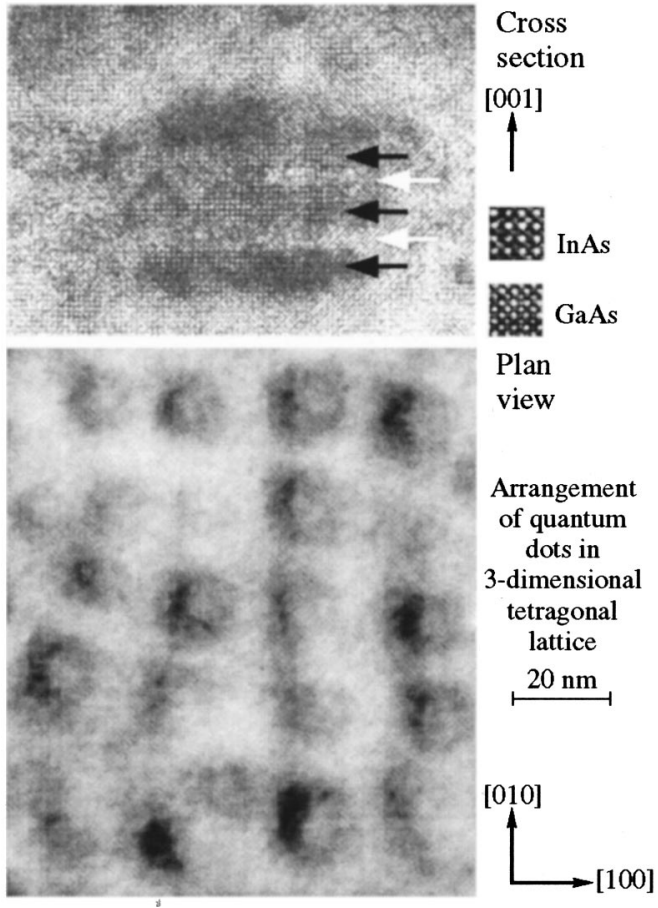

FIG. 15. Vertical and transverse ordering of coupled quantum dots in the system InAs-GaAs.

sequences. Short-period alternation in deposition of strained materials leads to a splitting of quantum dots and to formation of vertically coupled QD superlattice structures (Fig. 15; Alferov, Bert, et al., 1996). Groundstate quantum dot emission, absorption, and lasing energies are found to coincide (Ledentsov et al., 1995). The observation of ultranarrow $(<0.15 \mathrm{meV})$ luminescence lines from single quantum dots (Ledentsov et al., 1995) which do not exhibit broadening with temperature, is proof of the formation of an electronic quantum dot (Fig. 16).

Quantum dot lasers are expected to have properties superior to those of conventional quantum well lasers. High differential gain, ultralow threshold current density, and high-temperature stability of the threshold current density are expected to occur simultaneously. Additionally, ordered arrays of scatterers formed in an optical waveguide region may result in distributed feedback and/or in stabilization of single-mode lasing. Intrinsically buried quantum dot structures spatially localize carriers and prevent them from recombining nonradiatively at resonator faces. The overheating of facets, which is one of the most important problems for the high-power and high-efficiency operation of AlGaAs-GaAs and AlGaAs-InGaAs lasers, may thus be avoidable.

Since the first realization of QD lasers (Kirstaedter et al., 1994), it has become clear that the QD size uniformity was sufficient to achieve good device performance. But even at that time, it was recognized that the main obstacle for QD heterostructure laser operation at room and elevated temperatures was the temperature-induced evaporation of carriers from quantum dots. Different methods were developed to improve the laser perfor- 

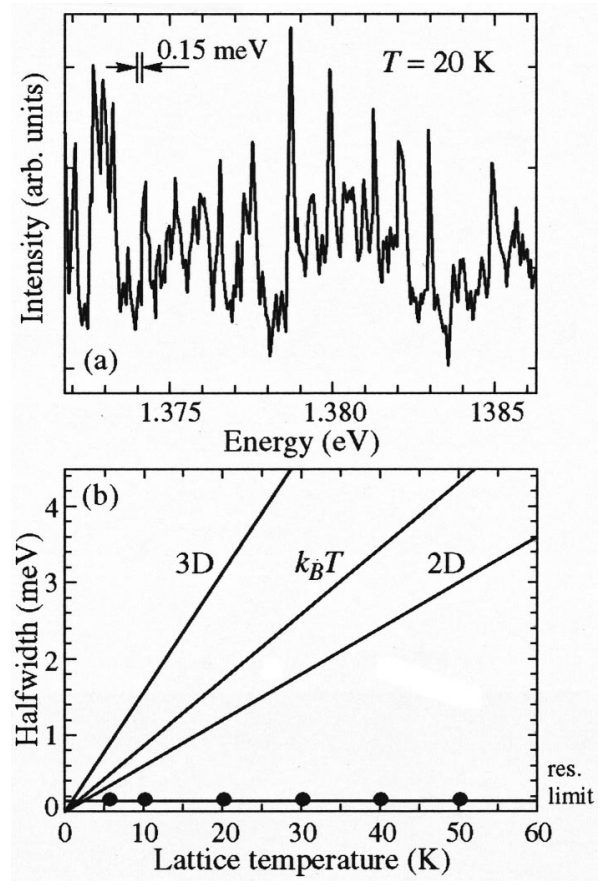

FIG. 16. (a) High-resolution cathodoluminescence spectrum of InAs-GaA; (b) temperature dependence of the full width at half-maximum of the cathode peak.

mance: (i) the increase of the density of quantum dots by stacking them (Fig. 17); (ii) the insertion of quantum dots into a quantum well sheet; (iii) the use of a matrix material with a higher band-gap energy. As a result, we got many parameters of QD heterostructure lasers better than those for quantum well heterostructure lasers based on the same materials. As an example, the worldrecord threshold current density of $19 \mathrm{~A} / \mathrm{cm}^{2}$ was recently achieved (Park et al., 2000). Further, a cw output power up to $3.5-4.0 \mathrm{~W}(\mathrm{cw})$ for a $100-\mu \mathrm{m}$ strip width, a quantum efficiency of $95 \%$ and a wall-plug efficiency of $50 \%$ were recently obtained (Zhukov et al., 1999).

Significant efforts towards a theoretical understanding of QD lasers with realistic parameters have been undertaken. For a QD size dispersion of about $10 \%$ and other

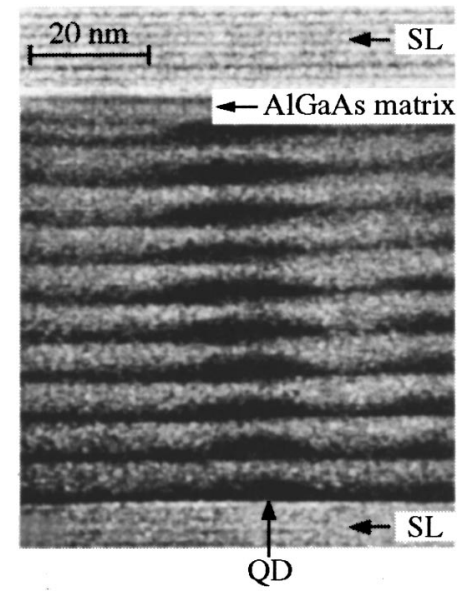

FIG. 17. Transmission electron microscopy image of the active region of high-intensity laser.
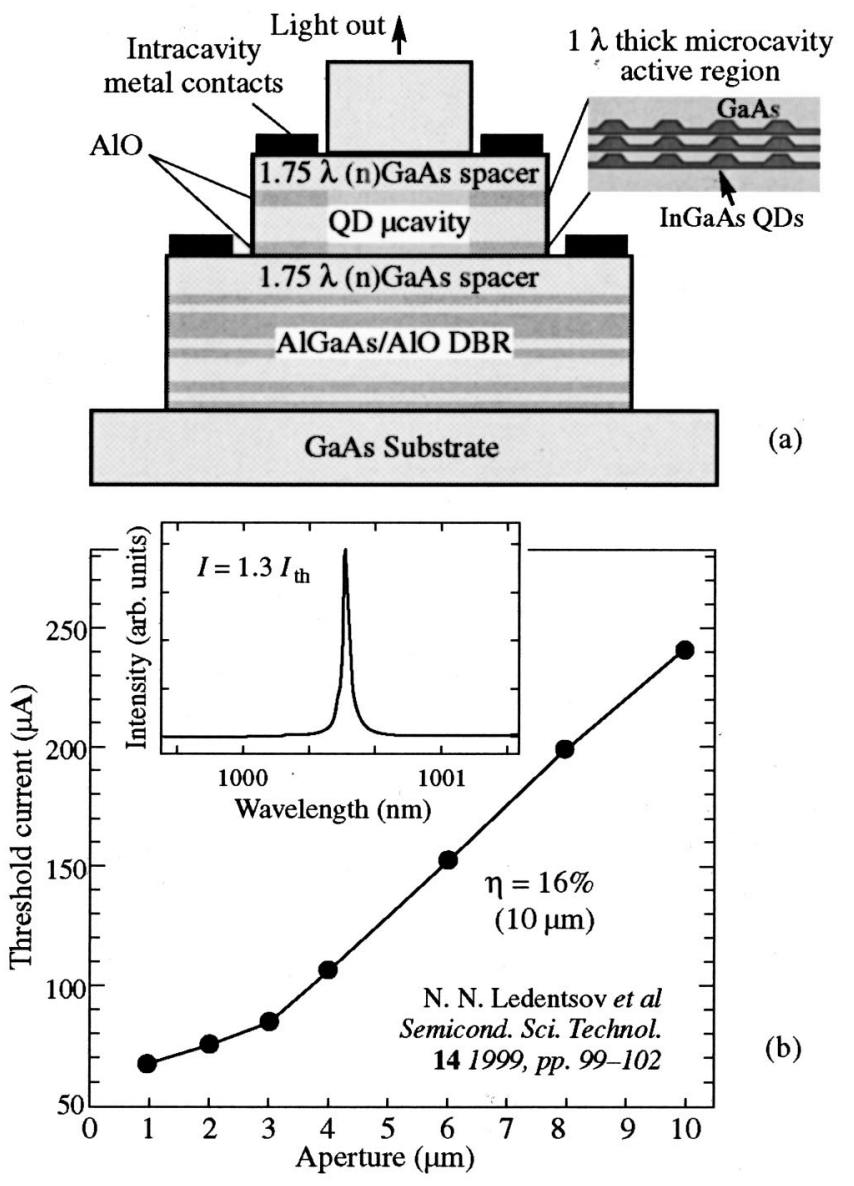

(b)

FIG. 18. (a) Schematic view of the quantum dot vertical-cavity surface-emitting laser structure. Basic advantages of quantum dots: (1) no interface recombination at oxide-defined apertures; (2) reduced lateral spreading of carriers out of the aperture region. Single quantum dot laser at ultralow threshold current is possible. (b) Dependence of the threshold current on the aperture size in a QD vertical-cavity surface-emitting laser. (i) Low threshold current densities $\left(170 \mathrm{~A} / \mathrm{cm}^{2}\right.$ at $\left.300 \mathrm{~K}\right)$; (ii) low threshold currents at ultrasmall apertures; (iii) $1.3-\mu \mathrm{m}$ range on GaAs substrate.

practical structure parameters, the theory (Asryan and Suris, 1996) predicts typical threshold current densities of $5 \mathrm{~A} / \mathrm{cm}^{2}$ at room temperature. The values of $10 \mathrm{~A} / \mathrm{cm}^{2}$ at $77 \mathrm{~K}$ (Zhukov et al., 1997) and even $5 \mathrm{~A} / \mathrm{cm}^{2}$ at $4 \mathrm{~K}$ (Park et al., 1999) have been experimentally observed.

In view of advanced device applications of quantum dots, the incorporation of quantum dots in verticalcavity surface-emitting lasers seems to be very important. QD vertical-cavity surface-emitting lasers with parameters that fit to the best values for quantum well devices of similar geometry have been demonstrated (Fig. 18; Lott et al., 1977). Recently, very promising results have been obtained (Fig. 19; Lott et al., 2000) for 1.3- $\mu \mathrm{m}$ QD vertical-cavity surface-emitting lasers on a GaAs substrate to use in fiber-optic communications.

In a free-standing 3D island formed on a latticemismatched substrate, the strains can relax elastically, without the formation of dislocations. Thus a sufficiently large volume of a coherent narrow-gap QD material can be realized. This makes it possible to cover a spectral 


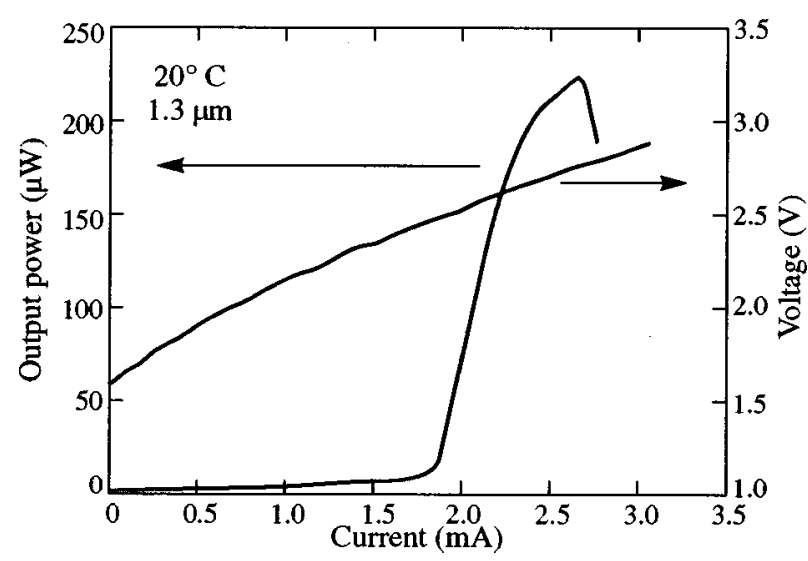

FIG. 19. GaAs-based QD vertical-cavity surface-emitting laser emitting at $1.3 \mu \mathrm{m}$.

range of 1.3-1.5 $\mu \mathrm{m}$ using a GaAs substrate and to develop wavelength-multiplexing systems on the basis of QD vertical-cavity surface-emitting lasers in the future.

It is very important to emphasize that we were able to realize the DHS concept for quantum wire and quantum dot structures because in both cases we have a narrow band-gap material in a wide-gap matrix.

Let us summarize again as we did for other parts.

\section{HETEROSTRUCTURE QUANTUM WIRES AND DOTS}

\section{Fundamental physical phenomena}

- 1D electron gas (wires)

- Density-of-state function with sharp maximums (wires)

- 0D electron gas (dots)

- $\delta$-function type of density-of-state function (dots)

- Increasing binding energy of excitons

\section{Important applications in electronics}

- Reduced lasing threshold current and larger differential gain

- Reduced temperature dependence of threshold current (wires)

- Temperature stability of the threshold current (dots)

- Discrete amplification spectrum and a possibility of obtaining performance characteristics similar to those of solid-state or gas lasers (dots)

- Higher modulation factor in electro-optical modulators

- Possibility of creating "single-electron" devices

- A new possibility for the development of field-effect transistors

\section{Important technological peculiarities}

- The application of self-organization effects for growth

- Epitaxial growth in $\mathrm{V}$ grooves (wires)

- High-resolution lithography of heterostructure quantum well lasers

\section{FUTURE TRENDS}

Recently very impressive results for short-wavelength light sources have been achieved on the basis of II-VI selenides and III-V nitrides. The success in this research was mostly determined by the application of heterostructure concepts and methods of growth which had been developed for III-V quantum wells and superlattices. The natural and most predictable trend is the application of heterostructure concepts as well as technological methods and peculiarities of new materials. Different III-V, II-VI, and IV-VI heterostructures, developed in recent times, are good examples of this statement.

But from a more fundamental point of view, heterostructures (including quantum wells and superlattices, quantum wires, and quantum dots) offer a way to create new types of materials-hetero-semiconductors. In the words of Leo Esaki, instead of "God-made crystals" we create "man-made crystals."

The study of classical heterostructures, quantum wells and superlattices is quite mature and we are now exploiting many of their unique properties. The study of quantum wire and dot structures is still very young: exciting discoveries and new unexpected applications are awaiting us. Even at this early stage, however, we can say that ordered equilibrium arrays of quantum dots may be used in many devices: lasers, light modulators, far-infrared detectors and emitters, etc. Resonant tunneling via semiconductor atoms introduced in larger band-gap layers may lead to significant improvement in device characteristics. More generally speaking, QD structures will be developed both "in width" and "in depth."

In width means new material systems to cover a new energy spectrum. The lifetime limitations of the green and blue semiconductor lasers and even more general problems of the creation of defect-free structures based on wide-gap II-VI and III-V (nitrides) would be solved by using QD structures in these systems.

As to in depth, it is necessary to mention that the degree of ordering depends on very complicated growth conditions, materials constants, and concrete values of the surface free energy. To achieve resonant tunneling and single-electron devices, including optical ones, require a thorough investigation and evaluation of these parameters in order to obtain the maximal possible degree of ordering. In general, it is necessary to find stronger self-organization mechanisms for ordered arrays of quantum dots.

In the early 1980s I was invited to deliver a lecture about heterostructures and applications at the Amoco Photonic Center near Chicago.

The summary of my lecture was as follows:

(1) Heterostructures - a new kind of semiconductor material-expensive, complicated chemically and technologically, but most efficient

(2) Modern optoelectronics is based on heterostructure applications:

-The DHS laser-a key device of modern optoelectronics

-The heterostructure protodiode-the most efficient and high-speed photodiode 
-Optoelectronic integrated circuits (OEIC's) -will solve problem of high information density of an optical communication system

(3) Future high-speed microelectronics will mostly use heterostructures

(4) High-temperature, high-speed power electronics-a new broad field of heterostructure applications

(5) Heterostructures in solar energy conversion: the most expensive photocells and the cheapest solar electricity producer

(6) In the 21 st century heterostructures in electronics will reserve only $1 \%$ for homojunctions

And 20 years later I see no reason to change this summary.

It is hardly possible to describe even the main directions of modern physics and the technology of semiconductor heterostructures. There is much more than I have mentioned. Many scientists contributed to this tremendous progress, which defines to a great extent not only the future prospects of condensed-matter physics and semiconductor laser and communication technology, but also, in a sense, the future of human society. I would like also to emphasize the impact of scientists of previous generations who prepared our way. I am very happy that I had a chance to work in this field from the very beginning. I am even happier that we can continue to contribute to progress in this area now.

\section{REFERENCES}

Alferov, Zh. I., 1966, "Possible development of a rectifier for very high current densities on the bases of a $p-i-n$ $\left(p-n-n^{+}, n-p-p^{+}\right)$structure with heterojunctions," Fiz. Tekh. Poluprovodn. 1, 436 [Sov. Phys. Semicond. 1, 358 (1967)].

Alferov, Zh. I., 1970, "Electroluminescence of heavily-doped heterojunctions $p \quad \mathrm{Al}_{x} \mathrm{Ga}_{1-x}-n \mathrm{GaAs}$," J. Lumin. 1, 869.

Alferov, Zh. I., et al., 1974, "Laser with supersmall divergence of radiation," Fiz. Tekh. Poluprovodn. 8, 832 [Sov. Phys. Semicond. 8, 541 (1974)].

Alferov, Zh. I., et al., 1975, "Semiconductor laser with distributed feedback in second order," Pis'ma Zh. Tekh. Fiz. 1, 645 [Sov. Tech. Phys. Lett. 1, 286 (1975)].

Alferov, Zh. I., et al., 1985, "Auger-profiles and luminescence investigations of LPE grown InGaAsP-heterostructures with active regions $(1.5-5) \times 10^{-6} \mathrm{~cm}$," Fiz. Tekh. Poluprovodn. 19, 1108 [Sov. Phys. Semicond. 19, 679 (1985)].

Alferov, Zh. I., et al., 1986a, "AlGaAs-heterostructure quantum wells grown by low temperature LPE," Pis'ma Zh. Tekh. Fiz. 12, 1089 [Sov. Tech. Phys. Lett. 12, 450 (1986)].

Alferov, Zh. I., et al., 1986b, "Low threshold InGaAsP/InP separate confinement lasers $\lambda=1.3 \mu \mathrm{m}$ and $\lambda=1.55 \mu \mathrm{m}\left(j_{\text {th }}\right.$ =600-700 A.cm ${ }^{2}$ ), " Pis'ma Zh. Tekh. Fiz. 12, 210 [Sov. Tech. Phys. Lett. 12, 87 (1986)].

Alferov, Zh. I., et al., 1987, "Low threshold quantum well InGaAsP/GaAs separate confinement double heterostructure lasers formed by the LPE $\left(\lambda=0.86 \mu \mathrm{m}, j_{\text {th }}=90 \mathrm{~A} / \mathrm{cm}^{2}, L\right.$ $\left.=\infty ; j_{\mathrm{th}}=165 \mathrm{~A} / \mathrm{cm}^{2}, L=1150 \mu \mathrm{m}, 300 \mathrm{~K}\right)$," Fiz. Tekh. Poluprovodn. 21, 824 [Sov. Phys. Semicond. 21, 503 (1987)].

Alferov, Zh. I., et al., 1988a, "Quantum-well InGaAsP/GaAs $(\lambda=0.86: 0.78 \mu \mathrm{m}) \quad$ separate confinement lasers $\quad\left(j_{\text {th }}\right.$
$=100 \mathrm{~A} / \mathrm{cm}^{2}$, efficience=59\% )," Fiz. Tekh. Poluprovodn. 22, 1031 [Sov. Phys. Semicond. 22, 650 (1988)].

Alferov, Zh. I., et al., 1988b, "Reducing of the threshold current in GaAs-AlGaAs DHS SCH quantum well lasers $\left(j_{\text {th }}\right.$ $=52 \mathrm{~A} / \mathrm{cm}^{2}, T=300 \mathrm{~K}$ ) with quantum well restriction by short period superlattice of variable period," Pis'ma Zh. Tekh. Fiz. 14, 1803 [Sov. Tech. Phys. Lett. 14, 782 (1988)].

Alferov, Zh. I., F. A. Ahmedov, V. I. Korol'kov, and V. G. Nikitin, 1973, "Phototransistor utilizing a GaAs-AlAs heterojunction," Fiz. Tekh. Poluprovodn. 7, 1159 [Sov. Phys. Semicond. 7, 780 (1973)].

Alferov, Zh. I., V. M. Andreev, D. Z. Garbuzov, Yu. V. Zhilyaev, E. P. Morozov, E. L. Portnoi, and V. G. Trofim, 1970, "Investigation of the influence of the AlAs-GaAs heterostructure parameters on the laser threshold current and realization of continuous emission at room temperature," Fiz. Tekh. Poluprovodn. 4, 1826 [Sov. Phys. Semicond. 4, 1573 (1971)].

Alferov, Zh. I., V. M. Andreev, M. B. Kagan, I. I. Protasov, and V. G. Trofim, 1970, "Solar-energy converters based on $p-n$ $\mathrm{Al}_{x} \mathrm{Ga}_{1-x} \mathrm{As}-\mathrm{GaAs}$ heterojunctions," Fiz. Tekh. Poluprovodn. 4, 2378 [Sov. Phys. Semicond. 4, 2047 (1971)].

Alferov, Zh. I., V. M. Andreev, R. F. Kazarinov, E. L. Portnoi, and R. A. Suris, 1971, "Semiconductor optical quantum generator," Inventor's Certificate No. 392875 [in Russian], Application No. 1677436, priority as of July 19, 1971.

Alferov, Zh. I., V. M. Andreev, S. G. Konnikov, V. G. Nikitin, and D. N. Tret'yakov, 1971, "Heterojunctions on the base of $A^{\mathrm{III}} B^{\mathrm{V}}$ semiconducting and of their solid solutions," in Proceedings of the International Conference on Physics and Chemistry of Semiconductor Heterojunctions and Layer Structures, Budapest, October 1970, edited by G. Szigeti (Academiai Kiado, Budapest), Vol. 1, p. 93.

Alferov, Zh. I., V. M. Andreev, V. I. Korol'kov, V. G. Nikitin, and A. A. Yakovenko, 1970, " $p-n-p-n$ structures based on GaAs and on $\mathrm{Al}_{x} \mathrm{Ga}_{1-x}$ As solid solutions," Fiz. Tekh. Poluprovodn. 4, 578 [Sov. Phys. Semicond. 4, 481 (1971)].

Alferov, Zh. I., V. M. Andreev, V. I. Korol'kov, E. L. Portnoi, and D. N. Tret'yakov, 1968a, "Injection properties of $n-\mathrm{Al}_{x} \mathrm{Ga}_{1-x} \mathrm{As}-p$-GaAs heterojunctions," Fiz. Tekh. Poluprovodn. 2, 1016 [Sov. Phys. Semicond. 2, 843 (1969)].

Alferov, Zh. I., V. M. Andreev, V. I. Korol'kov, E. L. Portnoi, and D. N. Tret'yakov, 1968b, "Coherent radiation of epitaxial heterojunction structures in the AlAs-GaAs system," Fiz. Tekh. Poluprovodn. 2, 1545 [Sov. Phys. Semicond. 2, 1289 (1969)].

Alferov, Zh. I., V. M. Andreev, V. I. Korol'kov, E. L. Portnoi, and D. N. Tret'yakov, 1969, "Recombination radiation in epitaxial structures in the system AlAs-GaAs," in Proceedings of the Ninth International Conference on Semiconductor Structures, Moscow, July 23-29, 1968 [in Russian] (Nauka, Leningrad), Vol. 1, p. 534.

Alferov, Zh. I., V. M. Andreev, V. I. Korol'kov, E. L. Portnoi, and A. A. Yakovenko, 1969a, "Recombination radiation in $\mathrm{Al}_{x} \mathrm{Ga}_{1-x}$ As solid solutions with variable forbidden gap," Fiz. Tekh. Poluprovodn. 3, 541 [Sov. Phys. Semicond. 3, 460 (1970)].

Alferov, Zh. I., V. M. Andreev, V. I. Korol'kov, E. L. Portnoi, and A. A. Yakovenko, 1969b, "Spontaneous radiation sources based on structures with AlAs-GaAs heterojunctions," Fiz. Tekh. Poluprovodn. 3, 930 [Sov. Phys. Semicond. 3, 785 (1970)]. 
Alferov, Zh. I., V. M. Andreev, V. I. Korol'kov, D. N. Trat'yakov, and V. M. Tuchkevich, 1967, "High-voltage $p-n$ junctions in $\mathrm{Ga}_{x} \mathrm{Al}_{1-x}$ As crystals," Fiz. Tekh. Poluprovodn. 1, 1579 [Sov. Phys. Semicond. 1, 1313 (1968)].

Alferov, Zh. I., V. M. Andreev, E. L. Portnoi, and M. K. Trukan, 1969, "AlAs-GaAs heterojunction injection lasers with a low room-temperature threshold," Fiz. Tekh. Poluprovodn. 3, 1328 [Sov. Phys. Semicond. 3, 1107 (1970)].

Alferov, Zh. I., I. N. Arsent'ev, D. Z. Garbuzov, S. G. Konnikov, and V. D. Rumyantsev, 1975a, "Generation of coherent radiation in $n \mathrm{Ga}_{0.5} \operatorname{In}_{0.5} \mathrm{P}$ $p \mathrm{Ga}_{x \sim 0.55} \mathrm{In}_{1-x} \mathrm{As}_{y \sim 0.10} \mathrm{P}_{1-y}-n \mathrm{Ga}_{0.5} \mathrm{In}_{0.5} \mathrm{P}$, " Pis'ma Zh. Tekh. Fiz. 1, 305 [Sov. Tech. Phys. Lett. 1, 147 (1975)].

Alferov, Zh. I., I. N. Arsent'ev, D. Z. Garbuzov, S. G. Konnikov, and V. D. Rumyantsev, 1975b, "Red injection heterolasers in the Ga-In-As-P system," Pis'ma Zh. Tekh. Fiz. 1, 406 [Sov. Tech. Phys. Lett. 1, 191 (1975)].

Alferov, Zh. I., N. A. Bert, A. Yu. Egorov, A. E. Zhukov, P. S. Kop'ev, A. O. Kosogov, I. L. Krestnikov, N. N. Ledentsov, A. V. Lunev, M. V. Maksimov, A. V. Sakharov, V. M. Ustinov, A. F. Tsatsul'nikov, Yu. M. Shernyakov, and D. Bimberg, 1996, "An injection heterojunction laser based on arrays of vertically coupled InAs quantum dots in a GaAs matrix," Fiz. Tekh. Poluprovodn. 30, 351 [Sov. Phys. Semicond. 30, 194 (1996)].

Alferov, Zh. I., D. Z. Garbuzov, V. S. Grigor'ev, Yu. V. Zhilyaev, L. V. Kradinova, V. I. Korol'kov, E. P. Morozov, O. A. Ninua, E. L. Portnoy, V. D. Prochukhan, and M. K. Trukan, 1967, "Injection luminescence of epitaxial heterojunctions in the GaP-GaAs system," Sov. Phys. Solid State 9, 208.

Alferov, Zh. I., D. Z. Garbuzov, E. P. Morozov, and E. L. Portnoi, 1969, "Diagonal tunneling and polarization of radiation in $\mathrm{Al}_{x} \mathrm{Ga}_{1-x} \mathrm{As}-\mathrm{GaAs}$ heterojunctions and in GaAs $p-n$ junctions," Fiz. Tekh. Poluprovodn. 3, 1054 [Sov. Phys. Semicond. 3, 885 (1970)].

Alferov, Zh. I., N. Yu. Gordeev, S. V. Zaitsev, P. S. Kop'ev, I. V. Kochnev, V. V. Khomin, I. L. Krestnikov, N. N. Ledentsov, A. V. Lunev, M. V. Maksimov, S. S. Ruvimov, A. V. Sakharnov, A. F. Tsatsul'nikov, Yu. M. Shernyakov, and D. Bimberg, 1996, "A low-threshold injection heterojunction laser based on quantum dots, produced by gas-phase epitaxy from organometallic compounds," Fiz. Tekh. Poluprovodn. 30, 357 [Sov. Phys. Semicond. 30, 197 (1996)].

Alferov, Zh. I., and R. F. Kazarinov, 1963, "Semiconductor laser with electric pumping," Inventor's Certificate No. 181737 [in Russian], Application No. 950840, priority as of March 30, 1963.

Alferov, Zh. I., V. B. Khalfin, and R. F. Kazarinov, 1966, “A characteristic feature of injection into heterojunctions," Fiz. Tverd. Tela 8, 3120 [Sov. Phys. Solid State 8, 2480 (1967)].

Alferov, Zh. I., Yu. V. Zhilyaev, and Yu. V. Shmartsev, 1971, "The splitting of the conduction band in 'superlattice' on the base $\mathrm{GaP}_{x} \mathrm{As}_{1-x}$," Fiz. Tekh. Poluprovodn. 5, 196 [Sov. Phys. Semicond. 5, 174 (1971)].

Anderson, R. L., 1960, "Germanium-gallium arsenide heterojunctions," IBM J. Res. Dev. 4, 283.

Anderson, R. L., 1962, "Experiments on Ge-GaAs heterojunctions," Solid-State Electron. 5, 341.

Antipas, G. A., R. L. Moon, L. W. James, J. Edgecumbe, and R. L. Bell, 1973, "In gallium arsenide and related compounds," Inst. Phys. Conf. Ser. 17, 48.

Arakawa, Y., and H. Sakaki, 1982, "Multidimensional quantum well laser and temperature dependence of its threshold current," Appl. Phys. Lett. 40, 939.

Asryan, L. V., and R. A. Suris, 1996, "Inhomogeneous line broadening and the threshold current density of a semiconductor quantum dot laser," Semicond. Sci. Technol. 11, 554.

Baranov, A. N., et al., 1986, "Generation of coherent radiation in quantum-sized structure of the single heterojunction," Fiz. Tekh. Poluprovodn. 20, 2217 [Sov. Phys. Semicond. 20, 1385 (1986)].

Basov, N. G., O. N. Krokhin, and Yu. M. Popov, 1961, "The possibility of use of indirect transitions to obtain negative temperature in semiconductors," Sov. Phys. JETP 12, 1033.

Blum, A. I., N. P. Mokrovsky, and A. R. Regel, 1952, "The study of the conductivity of the semiconductors and intermetallic compounds in solid and liquid state," Izv. Akad. Nauk SSSR, Ser. Fiz. 16, 139.

Bogatov, A. P., L. M. Dolginov, L. V. Druzhinina, P. G. Eliseev, L. N. Sverdlova, and E. G. Shevchenko, 1974, "Heterolasers on the base of solid solutions $\mathrm{Ga}_{x} \mathrm{In}_{1-x} \mathrm{As}_{4} \mathrm{P}_{1-y}$ and $\mathrm{Al}_{x} \mathrm{Ga}_{1-x} \mathrm{Sb}_{y} \mathrm{As}_{1-y}$," Kvant. Elektron. 1, 2294 [Sov. J. Quantum Electron. 1, 1281 (1974)].

Chang, L. L., L. Esaki, W. E. Howard, and R. Ludke, 1973, "Growth of GaAs-GaAlAs superlattices," J. Vac. Sci. Technol. 10, 11.

Chang, L. L., L. Esaki, and R. Tsu, 1974, "Resonant tunneling in semiconductor double barriers," Appl. Phys. Lett. 24, 593. Cho, A. Y., 1971a, "Film deposition by molecular beam techniques," J. Vac. Sci. Technol. 8, 31.

Cho, A. Y., 1971b, "Growth of periodic structures by the molecular-beam method," Appl. Phys. Lett. 19, 467.

Davydov, B. I., 1939, "Contact resistance of semiconductors," Zh. Eksp. Teor. Fiz. 9, 451.

Delagebeaudeuf, D., et al., 1980, “Two-dimensional electron gas MESFET structure,” Electron. Lett. 16, 667.

Dingle, R., H. L. Stormer, H. L. Gossard, and W. Wiegmann, 1978, "Electron mobilities in modulation-doped semiconductor heterojunction superlattices," Appl. Phys. Lett. 33, 665.

Dingle, R., W. Wiegmann, and C. H. Henry, 1974, "Quantized states of confined carriers in very thin $\mathrm{Al}_{x} \mathrm{Ga}_{1-x} \mathrm{As}-$ GaAs- $\mathrm{Al}_{x} \mathrm{Ga}_{1-x} \mathrm{As}$ heterostructures," Phys. Rev. Lett. 33, 827.

Dupuis, R. D., and P. D. Dapkus, 1977, "Room temperature operation of $\mathrm{Ga}_{1-x} \mathrm{Al}_{x} \mathrm{As} / \mathrm{GaAs}$ double-heterostructure lasers grown by metalorganic chemical vapor deposition," Appl. Phys. Lett. 31, 466.

Dupuis, R. D., P. D. Dapkus, N. Holonyak, Jr., E. A. Rezek, and R. Chin, 1978, "Room temperature operation of quantum-well $\mathrm{Ga}_{1-x} \mathrm{Al}_{x} \mathrm{As}-\mathrm{GaAs}$ laser diodes grown by metalorganic chemical vapor deposition," Appl. Phys. Lett. 32, 295.

Ekimov, A. I., and A. A. Onushchenko, 1981, "Quantum size effect in three dimensional microscopic semiconductor crystals," JETP Lett. 34, 345.

Esaki, L., and L. L. Chang, 1974, "New transport phenomenon in a semiconductor 'superlattice,', Phys. Rev. Lett. 33, 686.

Esaki, L., and R. Tsu, 1970, "Superlattice and negative differential conductivity,” IBM J. Res. Dev. 14, 61.

Faist, J., F. Capasso, D. L. Sivco, C. Sirtori, A. L. Hutchinson, and A. Y. Cho, 1994, "Quantum cascade laser," Science 264, 553.

Fowler, A. B., F. F. Fang, W. E. Howard, and P. J. Stiles, 1966, "Magnetooscillatory conductance in silicon surfaces," Phys. Rev. Lett. 16, 901. 
Frenkel, Ya. I., 1931, "On the transformation of light into heat in solids,” Phys. Rev. 37, 17; 37, 1276.

Frenkel, Ya. I., 1936, "Light absorption and electrons and holes sticking in dielectric crystals," Zh. Eksp. Teor. Fiz. 6, 647.

Frenkel, Ya. I., and A. Ioffe, 1932, "On the electrical and photoelectric properties of contacts between a metal and semiconductor," Phys. Z. Sowjetunion 1, 60.

Garbuzov, D. Z., et al., 1988, “Technical Digest CLEO," Paper THU44, p. 396.

Garbuzov, D. Z., et al., 1990, Conference Digest 12th International Semiconductor Laser Conference, Davos, Switzerland, Paper L-33, p. 238.

Goldschmidt, V. M., 1929, "Crystal structure and chemical constitution," Trans. Faraday Soc. 25, 253.

Goldstein, L., F. Glas, J. Y. Marzin, M. N. Charasse, and G. Le Roux, 1985, "Growth by molecular beam epitaxy and characterization of InAs/GaAs strained-layer superlattices," Appl. Phys. Lett. 47, 1099.

Goryunova, N. A., 1951, "Seroe olovo" [Gray tin], Thesis (Leningrad State University, Physico-Technical Institute).

Gross, E. F., and N. A. Karryev, 1952a, "Light absorption by cuprous oxide crystal in infrared and visible spectrum," Dokl. Akad. Nauk SSSR 84, 261.

Gross, E. F., and N. A. Karryev, 1952b, "Exciton optical spectrum," Dokl. Akad. Nauk SSSR 84, 471.

Gubanov, A. I., 1950, "Theory of the contact between two semiconductors with different types of conduction," $\mathrm{Zh}$. Tekh. Fiz. 20, 1287.

Gubanov, A. I., 1951, "Theory of the contact of two semiconductors of the same type of conductivity," Zh. Tekh. Fiz. 21, 304.

Hall, R. H., G. E. Fenner, J. D. Kingsley, T. J. Soltys, and R. O. Carlson, 1962, "Coherent light emission from GaAs junction," Phys. Rev. Lett. 9, 366.

Hayashi, I., 1984, "Heterostructure lasers," IEEE Trans. Electron Devices ED-31, 1630.

Hayashi, I., M. B. Panish, P. W. Foy, and S. Sumski, 1970, "Junction lasers which operate continuously at room temperature," Appl. Phys. Lett. 17, 109.

Hitchens, W. R., N. Holonyak, Jr., P. D. Wright, and J. J. Coleman, 1975, "Low-threshold LPE $\mathrm{In}_{1-x^{\prime}} \mathrm{Ga}_{x^{\prime}} \mathrm{P}_{1-z^{\prime}} \mathrm{As}_{z^{\prime}} /$ $\mathrm{In}_{1-x} \mathrm{Ga}_{x} \mathrm{P}_{1-z} \mathrm{As}_{z} / \mathrm{In}_{1-x}, \mathrm{Ga}_{x^{\prime}} \mathrm{P}_{1-z^{\prime}} \mathrm{As}_{z^{\prime}}$ yellow doubleheterojunction laser diodes $\left(J<10^{4} \mathrm{~A} / \mathrm{cm}^{2}, I=5850 \mathrm{~A}, 77\right.$ K)," Appl. Phys. Lett. 27, 245.

Holonyak, N., Jr., and S. F. Bevacgua, 1962, "Coherent (visible) light emission from $\mathrm{Ga}\left(\mathrm{As}_{1-x} \mathrm{P}_{x}\right)$ junctions," Appl. Phys. Lett. 1, 83.

Hsieh, J. J., 1976, "Room-temperature operation GaInAsP/InP double-heterostructure diode lasers emitting at $1.1 \mu \mathrm{m}$," Appl. Phys. Lett. 28, 283.

James, L., G. Antipas, R. Moon, J. Edgecumbe, and R. L. Bell, 1973, "Photoemission from cesium-oxide-activated InGaAsP,” Appl. Phys. Lett. 22, 270.

Kazarinov, R. F., and R. A. Suris, 1971, "Possibility of the amplification of electromagnetic waves in a semiconductor with a superlattice," Fiz. Tekh. Poluprovodn. 5, 797 [Sov. Phys. Semicond. 5, 707 (1971)].

Kazarinov, R. F., and R. A. Suris, 1972a, "Electric and electromagnetic properties of semiconductors with a superlattice," Fiz. Tekh. Poluprovodn. 6, 148 [Sov. Phys. Semicond. 6, 120 (1972)].
Kazarinov, R. F., and R. A. Suris, 1972b, "Injection heterolaser with diffraction grating on contact surface," Fiz. Tekh. Poluprovodn. 6, 1359 [Sov. Phys. Semicond. 6, 1184 (1973)].

Kazarinov, R. F., and R. A. Suris, 1973, "Theory of electrical properties of semiconductors with superlattices," Fiz. Tekh. Poluprovodn. 7, 488 [Sov. Phys. Semicond. 7, 347 (1973)].

Keldysh, L. V., 1962, "Effect of ultrasonics on the electron spectrum of crystals," Fiz. Tverd. Tela. 4, 2265 [Sov. Phys. Semicond. 4, 1658 (1963)].

Kirstaedter, N., et al., 1994, "Low threshold, large $T_{0}$ injection laser emission from (InGa)As quantum dots," Electron. Lett. 30, 1416.

Klitzing, K. V., G. Dorda, and M. Pepper, 1980, "New method for high-accuracy determination of the fine-structure constant based on quantized Hall resistance," Phys. Rev. Lett. 45, 494. Kogelnik, H., and C. V. Shank, 1971, "Stimulated emission in a periodic structure," Appl. Phys. Lett. 18, 152.

Kroemer, H., 1957a, "Theory of a wide-gap emitter for transistors," Proc. IRE 45, 1535.

Kroemer, H. 1957b, "Quasi-electric and quasi-magnetic fields in a non-uniform semiconductor," RCA Rev. 28, 332.

Kroemer, H., 1963, "A proposed class of heterojunction injection lasers,” Proc. IEEE 51, 1782.

Kroemer, H., and G. Griffiths, 1983, "Staggered-lineup heterojunctions as sources of tunable below-gap radiation: Operating principle and semiconductor selection," IEEE Electron Device Lett. EDL-4, 1, 20.

Ledentsov, N. N., M. Grundmann, N. Kirstaedter, J. Christen, R. Heitz, J. Bohrer, F. Heinrichsdorff, D. Bimberg, S. S. Ruvimov, P. Werner, U. Richter, U. Gösele, J. Heydenreich, V. M. Ustinov, A. Yu. Egorov, M. V. Maximov, P. S. Kop'ev, and Zh. I. Alferov, 1995, "Luminescence and structural properties of (In,Ga)As-GaAs quantum dots," in Proceedings of the 22nd International Conference on the Physics of Semiconductors, Vancouver, Canada, 1994, edited by D. J. Lockwood (World Scientific, Singapore), Vol. 3, p. 1855.

Lott, J. A., N. N. Ledentsov, V. M. Ustinov, A. Yu. Egorov, A. E. Zhukov, P. S. Kop'ev, Zh. I. Alferov, and D. Bimberg, 1997, "Vertical cavity lasers based on vertically coupled quantum dots," Electron. Lett. 33, 1150.

Lott, J. A., N. N. Ledentsov, V. M. Ustinov, N. A. Maleev, A. E. Zhukov, A. R. Kovsh, M. V. Maximov, B. V. Volovik, Zh. I. Alferov, and D. Bimberg, 2000, "InAs-InGaAs quantum dot VCSELs on GaAs substrates emitting at $1.3 \mu \mathrm{m}$," Electron. Lett. 36, 1384.

Ludowise, M., W. T. Dietze, C. K. Lewis, M. D. Camras, N. Holonyak, Jr., B. K. Fuller, and M. A. Nixon, 1983, "Continuous $300 \mathrm{~K}$ laser operation of strained superlattices," Appl. Phys. Lett. 42, 487.

Lutskii, V. N., 1970, "Quantum-size effect-present state and perspective on experimental investigations," Phys. Status Solidi A 1, 199.

Manasevit, H. M., 1968, "Single crystal GaAs on insolating substrates," Appl. Phys. Lett. 12, 156.

Mimura, T., S. Hiyamizu, T. Fuji, and K. Nanbu, 1980, “A new field-effect transistor with selectively doped $\mathrm{GaAs} / n-\mathrm{Al}_{x} \mathrm{Ga}_{1-x} \mathrm{As}$ heterojunctions," Jpn. J. Appl. Phys. 19, L225.

Nakamura, M., A. Yariv, H. W. Yen, S. Somekh, and H. L. Garvin, 1973, "Optically pumped GaAs surface laser with corrugation feedback," Appl. Phys. Lett. 22, 315. 
Nasledov, D. N., A. A. Rogachev, S. M. Ryvkin, and B. V. Tsarenkov, 1962, "Recombination radiation of galiun arsenic," Fiz. Tverd. Tela 4, 1062 [Sov. Phys. Solid State 4, 782 (1962)].

Nathan, M. I., W. P. Dumke, G. Burns, F. H. Dill, Jr., and G. I. Lasher, 1962, "Stimulated emission of radiation from GaAs $p-n$ junctions," Appl. Phys. Lett. 1, 62.

Natta, G., and L. Passerini, 1928, Gazz. Chim. Ital. 58, 458.

Osbourn, G., 1982, "Strained-layer superlattices from lattice mismatched materials," J. Appl. Phys. 53, 1586.

Park, G., O. B. Shchekin, S. Csutak, D. L. Huffaker, and D. Deppe, 1999, "Room-temperature continuous-wave operation of a single-layered $1.3 \mu \mathrm{m}$ quantum dot laser," Appl. Phys. Lett. 75, 3267.

Park, G., O. B. Shchekin, D. L. Huffaker, and D. G. Deppe, 2000, "Low threshold oxide-confined $1.3 \mu \mathrm{m}$ quantum dot laser," IEEE Photonics Technol. Lett. 33, 230.

Rezek, E., H. Shichijo, B. A. Vojak, and N. Holonyak, 1977, "Confined-carrier luminescence of a thin $\mathrm{In}_{1-x} \mathrm{Ga}_{x} \mathrm{P}_{1-z} \mathrm{As}_{z}$ well $\left(x_{0} \sim 0.13, z \sim 0.29, \sim 400 \mathrm{~A}\right)$ in an InP $p-n$ junction," Appl. Phys. Lett. 31, 534.

Rupprecht, H. S., J. M. Woodall, and G. D. Pettit, 1967, "Efficient visible electroluminescence at $300 \mathrm{~K}$ from $\mathrm{Ga}_{1-x} \mathrm{Al}_{x} \mathrm{As}$ $p-n$ junctions grown by liquid-phase epitaxy," Appl. Phys. Lett. 11, 81.

Scifres, D. R., R. D. Burnham, and W. Streifer, 1974, "Distributed-feedback single heterojunction GaAs diode laser," Appl. Phys. Lett. 25, 203.

Shchukin, V. A., N. N. Ledentsov, P. S. Kop'ev, and D. Bimberg, 1995, "Spontaneous ordering of arrays of coherent strained islands," Phys. Rev. Lett. 75, 2968.

Shockley, W., 1951, "Circuit element utilizing semiconductor material," U.S. Patent 2269347, September 25.

Shriffer, J. R., 1957, "Semiconductor surface physics," in Pro- ceedings of the Conference on the Physics of Semiconductor Surfaces, Philadelphia, June 1956, edited by R. H. Kingston (University of Pennsylvania, Philadelphia), p. 68.

Tsang, W. T., 1982, "Extremely low threshold (AlGa)As graded-index waveguide separate-confinement heterostructure lasers grown by molecular-beam epitaxy," Appl. Phys. Lett. 40, 217.

Tsu, R., and L. Esaki, 1973, "Tunneling in finite superlattice," Appl. Phys. Lett. 22, 562.

Tsui, D. C., H. L. Stormer, and A. C. Gossard, 1982, "Two dimensional magnetotransport in the extreme quantum limit," Phys. Rev. Lett. 48, 1559.

van der Ziel, J. P., R. Dingle, R. C. Miller, W. Wiegmann, and W. A. Nordland, Jr., 1975, "Laser oscillations from quantum states in very thin $\mathrm{GaAs}-\mathrm{Al}_{0.2} \mathrm{Ga}_{0.8} \mathrm{As}$ multilayer structures," Appl. Phys. Lett. 26, 463.

Welker, N. H., 1939, "Uber neue halblestende Verbindungen" [New semiconductor compounds], Z. Naturforsch. A 7a, 744; 1953, Z. Naturforcsch A 8a, 248.

Zhukov, A. E., A. R. Kovsh, S. S. Mikhrin, N. A. Maleev, V. M. Ustinov, D. A. Lifshits, I. S. Tarasov, D. A. Bedarev, M. V. Maximov, A. F. Tsatsul'nikov, I. P. Soshnikov, P. S. Kop'ev, Zh. I. Alferov, N. N. Ledentsov, and D. Bimberg, 1999, "3.9 W CW power from submonolayer quantum dot diode laser," Electron. Lett. 35, 1845.

Zhukov, A. E., V. M. Ustinov, A. Yu. Egorov, A. R. Kovsh, A. F. Tsatsul'nikov, N. N. Ledenstov, S. V. Zaitsev, N. Yu. Gordeev, P. S. Kop'ev, and Zh. I. Alferov, 1997, "Negative characteristic temperature of InGaAs quantum dot injection laser,” Jpn. J. Appl. Phys., Part 1 36, 4216.

Zhuze, V. P., and I. V. Kurchatov, 1932a, "To question about conductivity of cuprous oxide," Zh. Eksp. Teor. Fiz. 2, 309.

Zhuze, V. P., and I. V. Kurchatov, 1932a, "Zur electrischen Leitfahigkeit von Kupferoxydul," Phys. Z. Sowjetunion 2, 453. 